OPEN ACCESS

Edited by:

Elva G. Escobar-Briones,

National Autonomous University

of Mexico, Mexico

Reviewed by:

Brennan Phillips,

The University of Rhode Island,

United States

Thanos Dailianis,

Hellenic Centre for Marine Research (HCMR), Greece

${ }^{*}$ Correspondence:

Dianne L. McLean

d.mclean@aims.gov.au

Specialty section:

This article was submitted to Marine Ecosystem Ecology,

a section of the journal

Frontiers in Marine Science

Received: 12 August 2019

Accepted: 20 March 2020

Published: 15 April 2020

Citation:

McLean DL, Parsons MJG, Gates AR, Benfield MC, Bond T, Booth DJ, Bunce M, Fowler AM,

Harvey ES, Macreadie PI,

Pattiaratchi $C B$, Rouse $S$,

Partridge JC, Thomson PG

Todd VLG and Jones DOB (2020)

Enhancing the Scientific Value of Industry Remotely Operated Vehicles (ROVS) in Our Oceans.

Front. Mar. Sci. 7:220

doi: 10.3389/fmars.2020.00220

\section{Enhancing the Scientific Value of Industry Remotely Operated Vehicles (ROVs) in Our Oceans}

\author{
Dianne L. McLean $1,2 *$, Miles J. G. Parsons 1,2 , Andrew R. Gates ${ }^{3}$, Mark C. Benfield ${ }^{4}$, \\ Todd Bond ${ }^{2,5}$, David J. Booth ${ }^{6}$, Michael Bunce ${ }^{7,8}$, Ashley M. Fowler ${ }^{6,9,10}$, Euan S. Harvey ${ }^{8}$, \\ Peter I. Macreadie ${ }^{9}$, Charitha B. Pattiaratchi ${ }^{2,11}$, Sally Rouse ${ }^{12}$, Julian C. Partridge ${ }^{2}$, \\ Paul G. Thomson ${ }^{2,11}$, Victoria L. G. Todd ${ }^{13,14}$ and Daniel O. B. Jones ${ }^{3}$
}

\begin{abstract}
'Australian Institute of Marine Science, Indian Ocean Marine Research Centre, Perth, WA, Australia, ${ }^{2}$ The UWA Oceans Institute, The University of Western Australia, Perth, WA, Australia, ${ }^{3}$ National Oceanography Centre, Southampton, United Kingdom, ${ }^{4}$ Department of Oceanography and Coastal Sciences, College of the Coast and Environment, Louisiana State University, Baton Rouge, LA, United States, ${ }^{5}$ School of Biological Sciences, The University of Western Australia, Perth, WA, Australia, ${ }^{6}$ School of Life Sciences, University of Technology Sydney, Sydney, NSW, Australia, ${ }^{7}$ Environmental Protection Authority, Wellington, New Zealand, ${ }^{8}$ School of Molecular and Life Sciences, Curtin University, Perth, WA, Australia, ${ }^{9}$ Centre for Integrative Ecology, School of Life and Environmental Sciences, Deakin University, Burwood, VIC, Australia, ${ }^{10}$ New South Wales Department of Primary Industries, Sydney Institute of Marine Science, Mosman, NSW, Australia, ${ }^{11}$ Oceans Graduate School, The University of Western Australia, Perth, WA, Australia, ${ }^{12}$ Scottish Association for Marine Science, Oban, United Kingdom, ${ }^{13}$ Ocean Science Consulting Limited, Dunbar, United Kingdom, ${ }^{14}$ Environmental Research Institute, University of the Highlands and Islands, Thurso, United Kingdom
\end{abstract}

Remotely operated vehicles (ROVs) are used extensively by the offshore oil and gas and renewables industries for inspection, maintenance, and repair of their infrastructure. With thousands of subsea structures monitored across the world's oceans from the shallows to depths greater than $1,000 \mathrm{~m}$, there is a great and underutilized opportunity for their scientific use. Through slight modifications of ROV operations, and by augmenting industry workclass ROVs with a range of scientific equipment, industry can fuel scientific discoveries, contribute to an understanding of the impact of artificial structures in our oceans, and collect biotic and abiotic data to support our understanding of how oceans and marine life are changing. Here, we identify and describe operationally feasible methods to adjust the way in which industry ROVs are operated to enhance the scientific value of data that they collect, without significantly impacting scheduling or adding to deployment costs. These include: rapid marine life survey protocols, imaging improvements, the addition of a range of scientific sensors, and collection of biological samples. By partnering with qualified and experienced research scientists, industry can improve the quality of their ROV-derived data, allowing the data to be analyzed robustly. Small changes by industry now could provide substantial benefits to scientific research in the long-term and improve the quality of scientific data in existence once the structures require decommissioning. Such changes also have the potential to enhance industry's environmental stewardship by improving their environmental management and facilitating more informed engagement with a range of external stakeholders, including regulators and the public.

Keywords: subsea infrastructure, biodiversity, ocean observation, underwater technology, science-industry partnerships 


\section{INTRODUCTION}

Advances in underwater technology have promoted increasingly comprehensive studies of our oceans and exploration to depths previously out of reach of humans (Marsh et al., 2013; Katija et al., 2017; Robert et al., 2017). A vast array of different underwater technologies now exists and are used, often for different purposes, by marine scientists and industries. However, oceanic scientific research, especially that conducted in the deep sea, remains costly in terms of logistics, personnel, and hardware, and restrictive spatially in terms of access to remote locations (e.g., Jones et al., 2013). The health of our oceans and sustainability of human activities therefore increasingly relies on the development of new technologies and cross-sector partnerships (Visbeck, 2018).

The offshore petroleum (oil and gas; O\&G) and renewable energy industries routinely use underwater technology for observation, control, and maintenance of infrastructure in locations otherwise unavailable to marine scientists (Jones, 2009). These activities increasingly use remotely operated vehicles (ROVs), with over 550 industry workclass ROVs in operation globally (IMCA, 2015; Figure 1). The numbers of heavy-duty ROVs available to the scientific community is dwarfed by those utilized by industry, particularly the O\&G sector. Moreover, industrial ROVs often remain at the same location for months to years whereas scientific systems deployed from a research vessel typically spend only a brief time at each study site. Annually, offshore industries invest billions of dollars collecting thousands of terabytes of data from ROVs, with much of these data archived within the companies involved and findings sequestered in commercially sensitive reports. These data remain an untapped resource, to investigate questions regarding the structure and function of offshore ecosystems, well beyond the purposes of their initial collection (Gates et al., 2017a; Macreadie et al., 2018). Consequently, industry-science partnerships that enable scientists to utilize and augment industry ROVs, and access collected data, have very high intrinsic value.

Industry is facilitating scientific research by providing ROV video that was originally collected purely for asset-maintenance purposes. Scientists utilize these historical industry ROV data to better understand the impact (both positive and negative) that the large numbers of static structures in our seas (offshore installations, including jackets, pipelines, wells, mattresses, etc.) have on marine ecology (Macreadie et al., 2018; McLean et al., 2018; Todd et al., 2018, 2019) and how this changes with time (McLean et al., 2017; Thomson et al., 2018). However, the extent and nature of industrial ROV operations is often not ideal for scientific analysis. For example, video resolution is frequently too poor, and illumination often too low, for species-level identification. As a result, data obtained from images are typically qualitative and descriptive, with identification to imprecise levels well above species. Even if raw video is of high-definition (HD) resolution, it is often downgraded to low resolution via down-sampling or compression to save archival space. Further, the distance of the ROV from the structure can limit its usefulness for identification of species. Closeup imagery of epibenthic organisms that often form complex "marine growth" habitats on offshore structures is required,

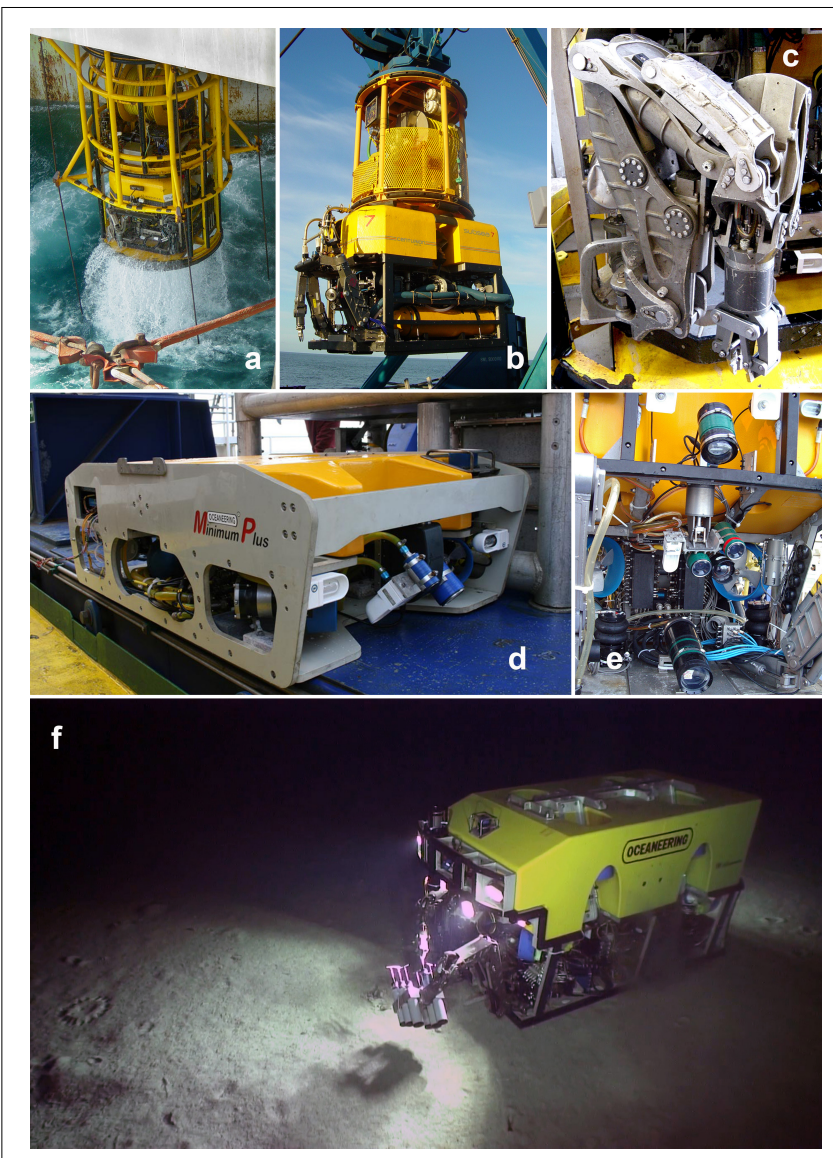

FIGURE 1 | Images of industrial ROVs photographed by the authors. (a) Subsea 7 work-class ROV ( $\sim 2 \mathrm{~m}$ tall) being deployed from the Transocean Jack Bates semi-submersible drilling rig. (b) Subsea 7 Centurion work-class ROV ( $2 \mathrm{~m}$ tall) on the MV Nordica. (c) Close up of Schilling Robotics Conan 7-function ROV manipulator ( $\sim 1 \mathrm{~m}$ tall as imaged). (d) Oceaneering Minimum Plus observation-class ROV ( $\sim 50 \mathrm{~cm}$ tall). (e) Detail of Oceaneering Magnum ROV ( $\sim 2 \mathrm{~m}$ tall) showing video and still cameras on pan-and-tilt unit (center) and lights. (f) Underwater image of Oceaneering Millennium ROV ( $\sim 2 \mathrm{~m}$ tall) taking push core samples of the seabed at around 1,700 $\mathrm{m}$ deep offshore Tanzania (taken with another ROV).

whereas for assessments of fish populations greater setback from the structure is necessary for abundance counts. Industry ROVs usually operate on a 24 -h schedule, and on an "as-required" basis and as such their timing may bias observations, particularly abundance estimates for species that exhibit diel and/or seasonal changes in behavior and population dynamics (Barker and Cowan, 2018; Bond et al., 2018a). Once imagery is obtained from industry, further challenges can be faced in video formatting for photogrammetric analysis and in spatially linking video to specific infrastructure components. For example, many industrial ROVs operate without ultra-short baseline (USBL) navigation systems that allow the ROV's position to be recorded in time and space and such information needs to be permanently tied to the video records if maximum value is to be obtained from the latter. There is an opportunity for these issues to be managed and for industry to obtain ROV video and associated metadata for their 
operational needs, while also providing useful data for research. This requires industry to understand what scientists need, and how scientifically useful their ROV video can be. Conversely, marine scientists need to understand better the operational practices of offshore industries if sensible proposals are to be made about changes to ROV operations. Such a bidirectional understanding will enable industry to adapt future inspection campaigns to enhance the collection of both industry-relevant and scientifically useful video.

Offshore O\&G structures used by industry have finite operational lives dictated by factors such as the size of underlying hydrocarbon reserves and mechanical lifetimes. Thousands of structures will require decommissioning globally over coming decades, with decommissioning activity already increasing rapidly in some regions (e.g., North Sea; Fowler et al., 2018). Data provided by ROVs will be essential for timely investigation of the ecological role of offshore infrastructure and to predict the environmental effects of their removal/abandonment. Further, improved understanding of how marine communities are utilizing artificial structures can, and should, influence future structural design and installation to maximize environmental, social, and economic benefits. For example, the midwater sections of platforms off California provide important habitat for the recruitment of fishery-important rockfishes (Sebastes spp.), which then move to deeper platform sections as they mature (Love et al., 2006). Increasing the surface area and complexity of midwater structure in the design of future offshore energy installations would likely enhance fish production at such sites (Claisse et al., 2014). In this regard, ROV imagery of infrastructure is required to quantitatively measure structural features, associated marine life and to reveal relationships between them. Understanding the drivers of fish populations and fish biomass "production" would also assist Operators "design for decommissioning."

This paper identifies and describes operationally feasible ways to adapt and augment routinely performed industry ROV operations to improve the use of industry-obtained data for science (Figure 2). Use of ROVs by scientists independent of industry is not discussed here; however, lessons learnt from the use of science ROVs are relevant and have informed methods described herein. This paper is prepared by research scientists with the view to ensuring that suggested future modifications to industry ROV operations are operationally feasible to implement and unlikely to significantly impact on scheduling and costs.

\section{ALIGNING EXPECTATIONS FOR SCIENCE-INDUSTRY COLLABORATION}

Strong partnerships between industry and academic scientists: i.e., relationships between project managers, engineers, industry scientists, and ROV operators are essential for successful collaborative projects. This is in part because a suite of specific, costly training courses and requirements (e.g., helicopter escape safety training and offshore medicals, Federal security clearances), coupled with prior offshore experience and strict client Non-Disclosure Agreements (NDAs) are often prerequisites for accessing offshore O\&G installations. Moreover, $500 \mathrm{~m}$ shipping-exclusion zones around many installations prevent outsider access. As a result, academic scientists are often precluded from accessing offshore assets, necessitating use of industry scientists and/or contractors to collect data. In these instances, academics can work with industry to develop succinct equipment operation instruction manuals or standard operating procedures and can perform trials to determine where difficulties in execution may occur. Consideration must be given to the expectations of ROV operators and industry partners if scientific data collection is to succeed and, in this regard, initial planning meetings and ongoing communication are essential.

A key role for ROVs in offshore drill-support operations is subsea asset integrity inspection. Such inspections provide an opportunity to document marine life growing on or living in close association with structures. Dives are performed regularly to inspect riser pipes, blow-out preventer (BOPs) and wells. Following such routine dives, ROVs are often on "standby", which presents an opportunity to perform scientific observations, at little to no extra cost to the client. Conversely, when ROVs perform "as found" seabed surveys on arrival at a new location, collection of scientific data during this period, while desirable, can cause delays to the start of operations, with unacceptable financial implications for the operator. However, where operators can look ahead at ROV schedules and include budget and time for dedicated science data collection into ROV campaigns, the resultant higher quality data can better inform environmental impact studies, decommissioning decisions and improve scientific understanding - a win-win for science and industry. For example, by collecting quantitative data on the conditions around a site prior to, and during drilling, an operator and regulatory agencies will have a much better baseline from which to assess changes to the environment due to routine activities or serious accidents.

In circumstances where ROV data collection cannot be completed independently by industry, researchers and industry could benefit from recent improvements in interactive video conferencing, which may allow researchers to interact with ROV pilots and guide ROV surveys remotely, thereby avoiding the cost and safety risks associated with visiting offshore installations. This model has been used effectively by scientific dives from the NOAA ship Okeanos Explorer where telepresence is used to enhance a small on-ship science team by communication with dozens of onshore experts during each ROV dive (Hoeberechts et al., 2015). The Inner Space Center is another example where telepresence is used to facilitate ocean exploration ${ }^{1}$. Internet access and bandwidth offshore are often limiting factors, and in the case of rig-moves, completely absent (i.e., no communications when satellite dishes are removed temporarily), so this level of communication is often not possible. If bandwidth is limited, latency may also present a challenge for remotely directed surveys because organisms of interest may not appear at the offshore and remote sites simultaneously.

\footnotetext{
${ }^{1}$ http://innerspacecenter.org/
} 


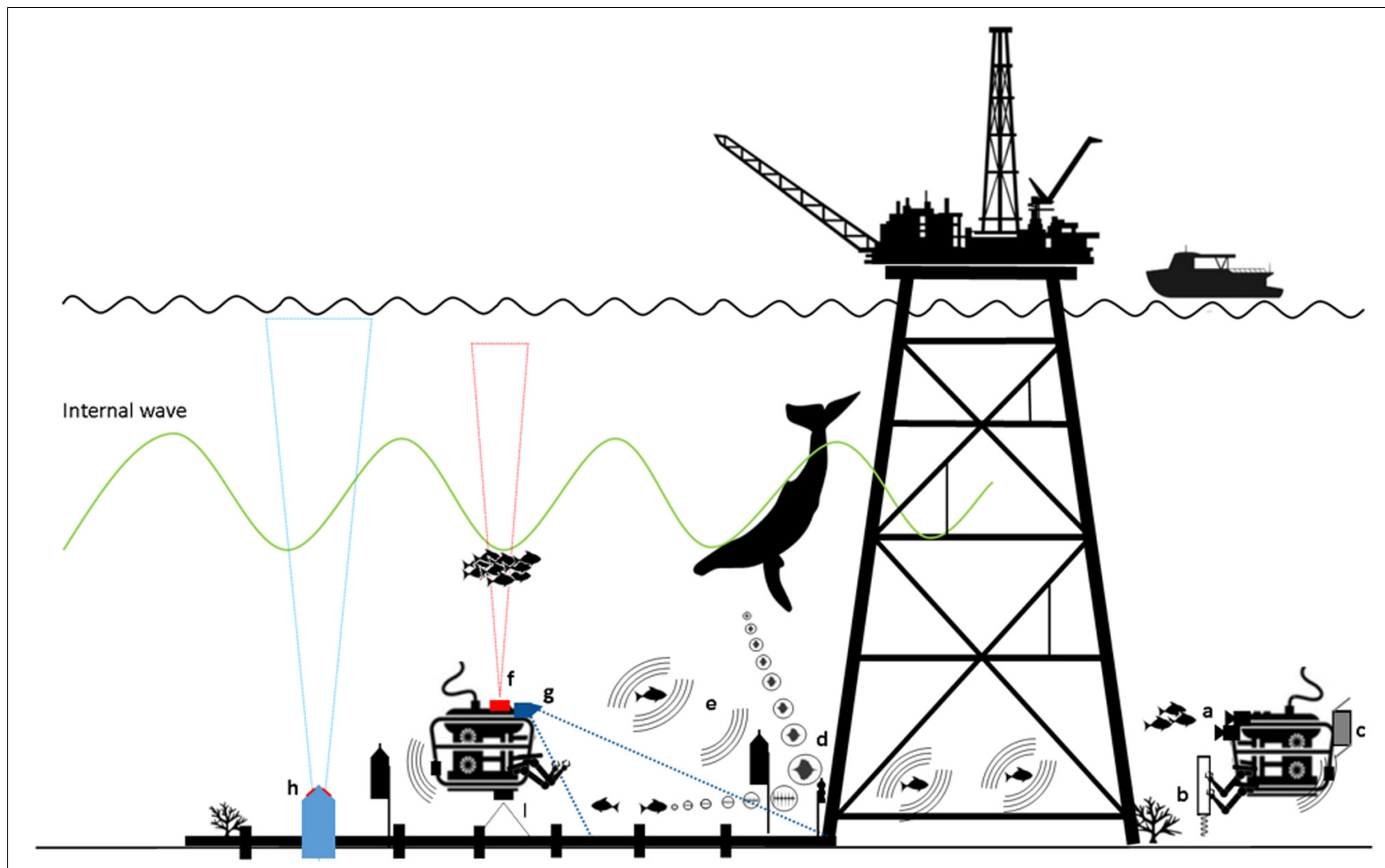

FIGURE 2 | Industrial remotely operated vehicles (ROVs) can be enhanced to collect scientific information through the addition of (a) high definition video and still photograph cameras; (b) sediment core samplers; (c) Niskin bottle water sampler; (d) passive acoustic monitoring; (e) acoustic telemetry tags and receivers; (f) echosounder; (g) forward-looking multibeam; (h) Acoustic Doppler current profilers (ADCP); (i) mapping multibeam. Diagram not to scale.

\section{AUGMENTING INDUSTRIAL ROVs FOR SCIENCE}

Industry ROV inspection activities include visual surveys but may also involve the use of manipulators to operate valves, changeover components, conduct cutting operations, and clear marine growth and debris (for example discarded fishing nets) (Figure $\mathbf{1}$ and Table 1). Inspections are often undertaken annually but can be more or less frequent depending on the risk level and maintenance requirements. There is an enormous opportunity to use and augment these capabilities to facilitate ocean research on both temporal-spatial scales, without compromising routine O\&G operations (Figure 2). A summary of augmentation approaches, the data they collect, and their feasibility are presented in Table $\mathbf{1}$.

All offshore industry instrumentation is subjected to rigorous risk assessment and must meet additional safety standards (e.g., explosion-proof). Any additional scientific instrument payload must be assessed for snagging hazard and stability testing. Further, if a standard industry ROV destined for a gas production platform survey is carrying any form of modification, such as additional cameras, all instruments must be pre-approved as "gas safe," i.e., a non-source of ignition; consequently, the $\mathrm{O} \& \mathrm{G}$ industry utilizes custom-made technology that is designed specifically for use in hydrocarbon-rich locations. These costly types of modifications are made at the manufacturing stage, with a consequence of longer manufacturing lead-times, and good forward planning. Pressure housings must be rated to the maximum depth of the offshore site with a safety factor. Such considerations are hitherto unforeseen hurdles to overcome for the scientific community, who are not subject to these types of environments and associated restrictions. Consequently, good communication regarding additional scientific requirements is required long before any actual modified ROV reaches its final deployment destination. Nevertheless, the scope for augmentation is considerable and such factors can be accommodated via close liaison with offshore operators (e.g., McLean et al., 2019).

\section{Enhanced Imaging Techniques}

To facilitate accurate identification of fish, marine growth and other fauna, ROVs should collect at least HD video. Traditionally, industry $\mathrm{ROV}$ operations do not require collection of $\mathrm{HD}$ imagery and, as a result, analysis of historical imagery for science is hampered by difficulties in species identification and counting due to low image resolution (e.g., Bond et al., 2018a; McLean et al., 2018; Thomson et al., 2018). Most modern ROVs possess the ability to record HD imagery and should do so as 
TABLE 1 | Key environmental indicators for assessment and the approach for obtaining them using industry ROV

\begin{tabular}{lll}
\hline Indicator & $\begin{array}{l}\text { Approach for measurement using } \\
\text { industry ROV }\end{array}$ & Feasibility \\
\hline $\begin{array}{l}\text { Bathymetry, seabed fabric and } \\
\text { structural mapping }\end{array}$ & ROV mounted sonar & $\begin{array}{l}\text { Low: Sector scanning sonar used as standard for navigation but not routine logging of data. } \\
\text { ROV-mounted multibeam used in some scientific applications. Typically done using } \\
\text { alternative approaches by industry. }\end{array}$
\end{tabular}

Seabed appearance

Sediment physicochemistry e.g., particle size, sediment chemistry

Seabed currents

Water column properties

Water column fauna

Epifauna (epigrowth) abundance and composition stereo-camera

Downward or horizontal-looking echosounders (e.g., mounted on structure)

Deployed ADCP/Upward-looking

echosounder

Acoustic telemetry

ROV photography / video

man grabs)

Use ROV to deploy and recover current

samplers (Niskin bottles)

CTD attached to ROV

ROV photography/video
High: Regular use of imagery for real-time visual characterization during routine inspection. Imagery regularly recorded. Standard approach for industry. Requirement for HD imagery. Medium: Use of sediment sampling equipment is straightforward but not standard. Depends on industry operations. Requires scientist to direct and process samples.

High: Instrument is deployed at the seabed using the ROV and recovered subsequently. Duration of deployment depends on time occupied at the station for ROV operations and could be up to 1 year.

Low: Water column sampling is straightforward and routine on scientific ROVs. It is rare on industry operations and equipment is not standard. Requires scientist to direct and process samples.

High: Instrument attached to ROV collects data whilst submerged. Data collected internally and only requires an operator switch on/off before and after each dive. Some industry ROV have built in CTD's but data extraction can be difficult. Additional sensors for chlorophyll, turbidity, dissolved organic carbon and dissolved oxygen are possible.

High: Quantitative mid-water video transects. Often serendipitous encounters with larger animals. Benefits from additional oceanographic sensor data collection.

Medium. Use of scientific-rate echosounder equipment is straightforward, but not standard. In situ calibration is an issue. Data can be post-processed.

Medium: Drilling operations often deploy ADCP for hydrographic assessment. Data rarely shared with scientists. Challenges with appropriate calibration for scientific requirements. Additional sensors can be added. Deployment of echosounder is similar to that of ADCP. Calibration is a potential issue. ADCP for current measurements are more common.

High: Potential for ROV to carry receiver unit and opportunistically detect tagged fauna or carry and an acoustic tag and provide opportunistic performance testing. ROV can deploy acoustic receivers along maintenance routes or in dedicated trips to produce an array.

High: Subsea structure inspection is routinely carried out using industry ROV. Many examples of scientific study of routine pipeline inspection video. This can provide

information about background faunal assemblages, oceanographic processes and the role of artificial structures.
References to support

industry us

Orange et al., 2002; Elvander and Hawkes, 2012; Allotta et al., 2015; Williams et al., 2016; Baran et al., 2017

Gates and Jones, 2012; Jones et al., 2014

Gates and Jones, 2012

Salim et al., 2018

Gallager et al., 2004

Benfield et al., 2009, 2013; Benfield and Graham, 2010; Hoving et al., 2013; Phillips et al., 2015; Jones and Pugh 2018; Kupchik et al., 2018

Stanley and Wilson, 2000;

Rose et al., 2005; Wilson et al., 2006; Fujii and Jamieson, 2016 Osborne et al., 1977; Scotti and Pineda, 2004; Jones et al. 2006; Li et al., 2009

Heupel et al., 2015; Hussey et al., 2015; Thums et al., 2016; Wilson et al., 2018 Guerin et al., 2007; Lebrato and Jones, 2009; McLean

et al., 2017, 2018; Bond et al., 2018a,d; Thomson et al., 2018 
TABLE 1 | Continued

\begin{tabular}{lll}
\hline Indicator & $\begin{array}{l}\text { Approach for measurement using } \\
\text { industry ROV }\end{array}$ & Feasibility \\
\hline
\end{tabular}

Specimen collection

Low: Collection of specimens from structures can enhance quality of studies of artificial

structures by improving identification of organisms, identifying associated organisms and measurement of biomass.

Epibenthic megafauna abundance and ROV photography / video

composition

High: Modification of routine as-found surveys can provide information on the pre-drilling seabed appearance. Scientist-directed ROV video transect surveys provide information about background faunal assemblages and how they change following anthropogenic impacts

Specimen collection

Low: Collection of specimens provides improved identification of poorly known fauna. This is particularly valuable in deep or other poorly explored areas where many species may be undescribed species.

Microbial/Infauna abundance and ROV sample collection (push cores Ekman grabs)

Low: Use of ROV sediment sampling equipment is straightforward but not standard. composition Sample collection is time-consuming and there is a requirement for processing at sea so needs scientist on board. Ability to collect these data depends on industry operations.

Medium: Real-time ROV observations are unlikely to be a good way of observing marine mammals, owing to behavioral modifications

Marine mammal abundance and composition

\section{Video assessments}

ROV-deployed hydrophones/ PAM

Medium: Installation or carrying of PAM is feasible but may be complicated by industrial noise in active areas and recovery of long-term moorings in inactive areas. Linking between industry and science can alleviate recovery of long-term moorings through the use of acoustic release systems.

Multibeam/imaging sonar

Imaging sonar systems can detect "targets" at greater ranges than visual techniques, reducing effect of ROV presence and noise; however, target identification is limited.

Fish abundance, behavior and

Archive (historical) video of structures

High: Use of historical video imagery of structures to quantify associated fish.

composition

ROV video in routine operations or drill support standby time

Mid-water photography/video

assessment

Deployment of standalone camera

ROV deployed hydrophones/ Passive acoustic monitoring

Acoustic telemetry

High: Fish surrounding drilling operations can be documented during chance encounters or targeted video transect surveys.

Medium: Deployment of bait to attract necrophagous species.

Low: Standalone camera for time-series observations.

Medium: In situ observations of fish are complicated by ROV and industrial noise. Behavioral effects from ROV presence and noise are similar to that of video and sonar observations. Installation or carrying of PAM is feasible but may be complicated by industrial noise in active areas and recovery of long-term moorings in inactive areas. Linking between industry and science can alleviate recovery of long-term moorings through the use of acoustic release systems.

High: Potential for ROV to carry receiver unit and opportunistically detect tagged fauna or carry and acoustic tag and provide opportunistic performance testing. ROV can deploy acoustic receivers along maintenance routes or in dedicated trips to produce an array.

Gates et al., 2019

Gates and Jones, 2012; Jones et al., 2013

Horton and Thurston, 2015

Nguyen et al., 2018

Todd et al., 2016

Todd et al., 2009, 2016; Erbe et al., 2015

Becker et al., 2013; Parsons et al., 2013, 2014; Lieber et al., 2015

McLean et al., 2017, 2018; Bond et al., 2018a; Thomson et al., 2018

Laurenson et al., 2004; Pradella et al., 2014

Benfield et al., 2008; Phillips

et al., 2015

Gates and Jones, 2012; Gates et al., 2017b

Rountree et al., 2002, 2003; Erbe et al., 2015; McCauley and Cato, 2016; Parsons et al. 2016; Todd et al., 2016

Topping and Szedlmayer, 2011; Piraino and Szedlmayer, 2014; Froehlich et al., 2019

For each approach, feasibility is assessed and references to existing studies provided. 


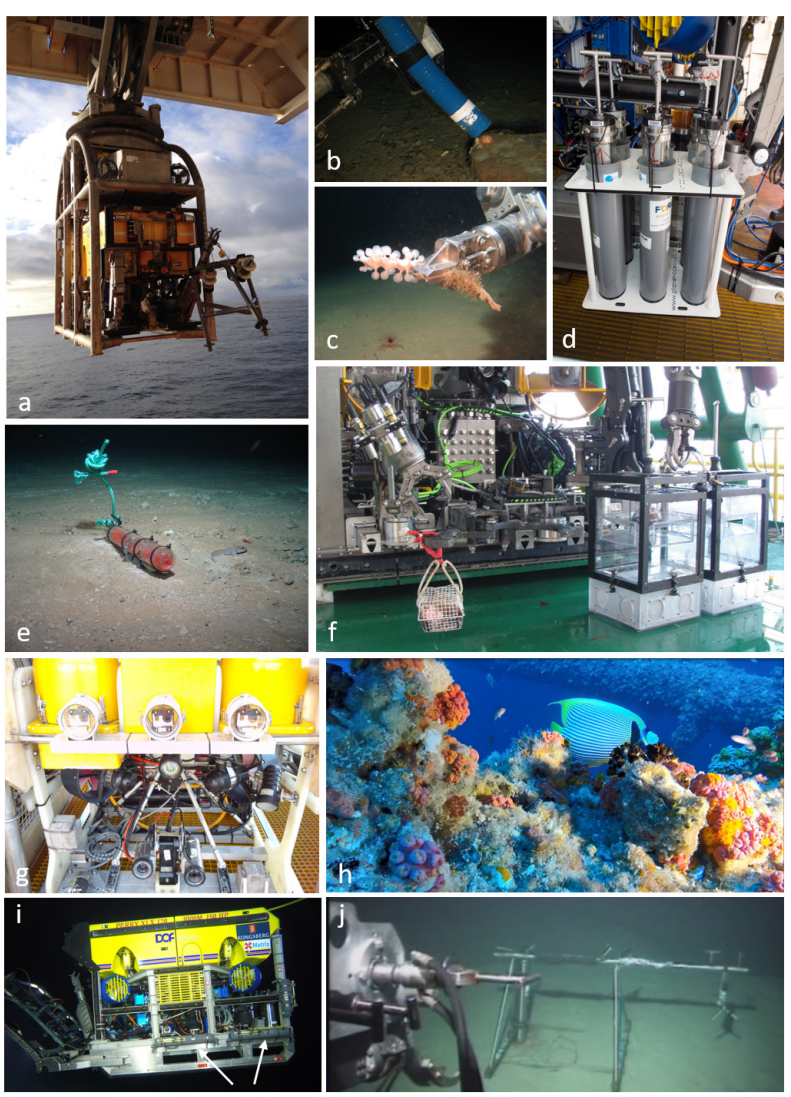

FIGURE 3 | Examples of how ROVs can be utilized to collect scientific information; (a) deployment of Oceaneering Magnum ROV holding a time-lapse camera system (to the right of the image) in 5-function manipulator arm, (b) modified zip pump for collecting fragile organisms (sea urchin pictured) suction tube attached to 5-function manipulator arm, (c) use of the 7-function ROV manipulator arm to collect specimens; (d) sediment core samplers, (e) deploying small traps to collect specimens (red scavenging isopods pictured), (f) bait cage and light traps to attract and capture organisms, (g) mounted stereo-video cameras to collect high definition imagery (h). (i) DOF Subsea ROV fitted with Niskin Bottles (indicated by arrows) from the Sydney-Kormoran Project Expedition 2015 provided courtesy of Curtin University and WA Museum@. WA Museum (j) ROV recovery of a current meter from the seabed at 375 m, after Salim et al. (2018).

standard practice. Although the acquisition of HD imagery is relatively straightforward, storage of $\mathrm{HD}$ data and its handling can add a significant indirect overhead and cost (see section "Data Management").

Additional video and digital still cameras can be mounted onto workclass ROVs for the specific purpose of collecting HD imagery that facilitates scientific research (McLean et al., 2019; Figures 2, 3G,H and Table 1). For example, McLean et al. (2019) recently added a compact stereo-video system onto a workclass ROV to collect HD imagery and enable accurate measurement of organisms' size. An ability to accurately measure size is particularly useful for assessing biomass, life-history stages of organisms and their ontogenetic shifts in habitat usage (Elliott et al., 2017), as well as the potential value of recreationally or commercially important fish species associated with offshore structures (Bond et al., 2018b,c). Stereo imagery also enables three-dimensional (3D) modeling of the environment which is important for describing both structures and marine growth, quantifying biological volumes, volumetric changes, and biological growth rates (Harvey and Shortis, 1995; Shortis and Harvey, 1998; Abdo et al., 2006). 3D HD video cameras have been developed (e.g., Oceaneering Ocean ProHD 3D imaging system) to provide the pilot with depth perception; however, these cameras also allow precise measurements of marine life to be performed. The addition of parallel lasers separated by a known distance (either point or line generators) is a simple and relatively inexpensive means of adding measurement capabilities to industrial ROVs. Such enhancements provide utility to the operator as well as for science.

The bright lights and loud sound produced by electrohydraulic ROVs may bias some surveys in favor of those taxa that do not actively avoid the vehicle. Under such circumstances, it may be useful to dim lights or equip the ROV with redfiltered lights. Widder et al. (2005) showed that an ROV equipped with red light was much less disruptive than white light for observations of deep sea sablefish (Anoplopoma fimbria). By shutting down the hydraulic pumps on an industrial ROV and using red-filtered lights, Benfield et al. (2019) were able to document the presence of additional fish species around a Gulf of Mexico rig that had not been detected during surveys with white lights while the ROV was running. Although additional lights and specialist cameras have proven value, careful consideration must be given to the location of such instruments added to an ROV to avoid interference with ROV operations, impacts of the ROV on the recordings made by added instruments (e.g., sound/lighting interference) and equipment damage.

\section{Acoustic Transmitters and Receivers}

Industry ROVs are well suited to carry and/or deploy certain types of acoustic sensors, which are extremely useful tools to census marine life on multiple spatial scales (Rountree et al., 2003; Koslow, 2009; Richardson et al., 2013; Hussey et al., 2015; Figure 2). Data acquisition is often autonomous, long-term, and non-interactive. Sensors can be mounted on ROVs or deployed to infrastructure or the seafloor and retrieved/redeployed on up to an annual basis (dependent on battery size, storage capacity, and recording schedule), to collect near-continuous temporal datasets at minimal effort (Table 1).

Passive acoustic monitoring (PAM) sensors (Figure 4A) can be carried or deployed by ROVs to monitor environmental noise around O\&G activities (Todd et al., 2009; Todd, 2016), to detect vocalizing marine fauna (see section "ROV Acoustic Surveys of Infrastructure and Surrounding Environments") or to evaluate ecosystem changes evident in the soundscape (Gordon et al., 2018) but the ROV's acoustics signature may sometimes interfere with such uses. ROVs can more easily be used to carry acoustic telemetry receivers (Figure 4B) to detect marine fauna with attached or implanted acoustic tags (Figure 4C) and help understand how these animals (e.g., whale sharks) may use infrastructure (Topping and Szedlmayer, 2011; Piraino and Szedlmayer, 2014; Froehlich et al., 2019; Table 1), which may have consequences for decommissioning. The previously 


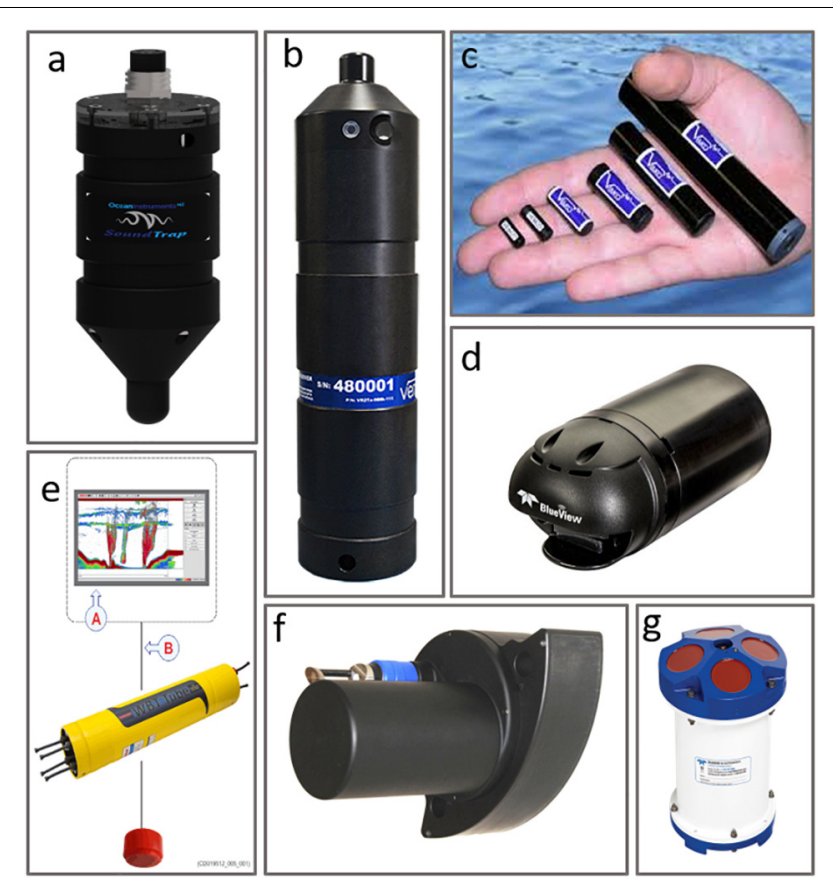

FIGURE 4 | Examples of acoustic instruments that can be attached to, or deployed by an industry ROV to collect scientific information including (a) Oceanlnstruments SoundTrap ST300 (PAM recorder), (b) Vemco acoustic telemetry receiver, (c) acoustic telemetry tags (Images courtesy of VEMCO, part of Innovasea), (d) Blueview M900-2250 imaging sonar (Images courtesy of Teledyne BlueView), (e) Simrad WBAT echosounder, (f) Norbit Subsea WBMS multibeam echosounder (for seafloor and water column), (g) Teledyne RDI ADCP (acoustic Doppler current profiler).

mentioned caveat regarding depth ratings of pressure housings is relevant here because most passive acoustic receivers are designed to operate in relatively shallow depths. Imaging sonars (Figure 4D) can be mounted on ROVs to provide seafloor textural information or to count and size targets in front of the ROV (see section "ROV Acoustic Surveys of Infrastructure and Surrounding Environments"). ROVs could also deploy single/splitbeam echosounders (Figure 4E) to evaluate biota in the water column and these have previously been mounted on and near O\&G platforms to estimate numbers of fish around the structures (e.g., Wilson et al., 2006). Alternatively, multibeam systems or sector side-scan sonars (Figure 4F) can acquire data from the water column above or below the ROV to map fauna targets (e.g., schools of fish or megafauna) or natural/anthropogenic structures (Baran et al., 2017). Longterm datasets from ROV-deployed acoustic Doppler current profilers (ADCPs; Figure $\mathbf{4 G}$ ) can provide oceanographic information pertinent to O\&G structures, such as currents, temperatures, acoustic backscatter, or the detection of internal waves (Li et al., 2009).

Such ROV-acoustic programs are not without limitations. There is currently limited understanding of the potential performance and range-limiting effects of noise around structures and from ROVs themselves (Rountree et al., 2002; Giacalone et al., 2005; Dziak et al., 2018), and little data on potential behavioral bias their presence may induce (Spanier et al., 1994). Some acoustic-related activities may require dedicated ROV time and the presence of a specialist to initiate these activities (e.g., range-testing telemetry arrays, programming recording schedules, calibrating echosounders) and in extreme cases (multibeam hydrography or water column) a specialist operator for data acquisition.

\section{ROVs as in situ Samplers}

Industry ROVs are well equipped to take samples of sediments and organisms from structures, the water column and the seafloor (Figure 1C) but may require additional equipment to store collected samples. Many workclass ROVs are equipped with a 7-function manipulator arm, which is dexterous and capable of precision sampling. Science-class ROVs (e.g., ROV Jason, ISIS, Holland) and human occupied vehicles (e.g., the Alvin submersible) typically use the same or similar 7-function manipulator arms (Figure 3C). Industry ROVs tend to also be equipped with a 5-function manipulator (Figures 3A,B), which is of less value in precision sampling, but can be used to hold sampling equipment. These arms can be used to either directly pick up robust objects or to hold specific tools for precision sampling, particularly for the collection of sediment or marine biological specimen samples.

The collection of marine specimens can aid identification of organisms and provide specimens for other biological studies. While some species are possible to identify from video, many require detailed examination of features that are not visible from images, for example because of orientation or resolution (Macreadie et al., 2018). In many areas, the species present are poorly characterized and may include undescribed species, making collections more important for identification. Specimen collection can be done using a wide range of methods, including suction samplers (Figure 3B), small manipulator-operated nets or core samplers (Figure 3D), and direct collections using the manipulators, micromanipulators (Figures 1C, 3C; Galloway et al., 2016) or traps (Figures 3E,F). In addition to making collections, it is also possible to directly introduce animals into experimental equipment to carry out in situ manipulative experiments using industrial ROVs (e.g., Hughes et al., 2010). Adding additional functionality to ROVs to collect multiple biological samples in a controlled manner (minimizing cross contamination) is an area requiring some engineering solutions.

In marine ecosystems, an emerging technology is the collection of "bulk" environmental samples (e.g., seawater, marine growth, or sediment) for genetic analysis and long-term biobanking (Jarman et al., 2018), of which ROVs will play an increasingly important role. For example, Figure 3I illustrates the use of ROV-mounted Niskin bottles for the collection of seawater. Environmental DNA (eDNA) is defined as all the genetic material that can be recovered from an environmental sample, which can originate from multiple species and from a variety of biological sources including: whole organisms, biological secretions, reproductive propagules, shed skin/hair, degrading tissue, or can exist as free DNA molecules (Taberlet et al., 2018). Once collected, information embedded within the DNA provides a lens through which to study the organisms that were 
present within that environment. Accordingly, the dependence of traditional biological surveys on retrieving whole organisms and complexities associated with morphological identification (i.e., time-consuming microscopy, difficulties identifying different life stages, sexes, and cryptic species) is largely overcome.

\section{ROVs as Oceanographic Samplers}

Oceanographic sensors can be mounted onto industry ROVs to collect data as the ROV travels through the water column or can be deployed by the ROV onto the seabed to collect data on near-bed conditions. Although many industry ROVs contain either CTD (Conductivity, Temperature, Depth) instruments or at least temperature sensors, extracting these data from the whole suite of data collected by the ROV has been problematic in the past. Alternatively, dedicated CTD instruments that may contain optional sensors to measure dissolved oxygen, chlorophyll, turbidity and dissolved organic matter can be mounted on the ROV and collect data autonomously (e.g., Gallager et al., 2004) and independent of ROV central systems. Additional sensors can be used, particularly low-power, cost-effective, highprecision sensors capable of deployment to depth and in rough conditions while still be able to relay information in real time. Such sensors can measure a whole range of oceanographic conditions including light, temperature, sound, mass, chemicals (including synthetic compounds and organic molecules), $\mathrm{pH}$, Eh, fluorescence, chlorophyll, etc. ROVs could also be used as a vehicle to deploy and recover oceanographic instruments on the seabed. Here, the instruments may be placed on the seafloor to collect data that include ocean currents and properties (e.g., CTD and optional sensors as described above). The duration of data collection is dependent on ROV activity and can extend from a few hours to months. Salim et al. (2018) described such a deployment on the north-west shelf of Australia to study sediment transport processes (Figure 3J). Such data from widely dispersed locations can yield meaningful datasets as evidenced by programs such as ARGO and ships of opportunity ${ }^{2}$ whilst also bridging knowledge gaps between oceanographic research and monitoring platforms elsewhere along coastlines.

\section{SCIENTIFIC SURVEYS OF INFRASTRUCTURE AND SURROUNDING ENVIRONMENTS USING AUGMENTED INDUSTRIAL ROVs}

In general, there are several different environments accessible to industry ROVs: the infrastructure and surrounding water column, the seafloor beneath and immediately surrounding infrastructure and undisturbed areas subject to O\&G exploration (Figure 2). Scientific evaluations in each of these environments are valuable and the areas impacted by industry activities are often inaccessible to any other approach.

For the seafloor, many locations accessible by industry ROVs have been subject to disturbance by industry or in some cases

${ }^{2}$ http://imos.org.au/ by natural activities (Lebrato and Jones, 2009; Jones and Brewer, 2012; Jones et al., 2014). These areas include those disturbed by sediment deposition (e.g., cuttings piles), physically altered by industry (e.g., covered in concrete during well construction or anchor scars in the sediment), and potentially chemical pollution (e.g., hydrocarbon release). Disturbed locations are generally small in spatial extent and difficult to access for scientific study, often being close to industry operations (Jones et al., 2007). As such, scientific information on these areas is limited and reliant on working with industry to better understand impacts from disturbance and recovery (Jones, 2009; Gates and Jones, 2012; Jones et al., 2012).

Offshore infrastructure and associated ROVs provide a rare opportunity to study reef ecosystems in deep water. Considerably less is known about reefs beyond depths accessible to divers, compared to those in shallow water, owing to logistical challenges and costs associated with their investigation (Brokovich et al., 2008). Vulnerability of deep reefs to anthropogenic impacts and environmental change also make them a priority for research (Roberts et al., 2006). Although unplanned, offshore installations can behave like artificial reefs and develop entire reef ecosystems during their operational life (Schroeder and Love, 2004; Macreadie et al., 2011). While they may not completely mimic natural reefs, these infrastructure ecosystems facilitate investigation of various aspects of community structure and function, including settlement processes, species composition, trophic dynamics and behavioral interactions (Macreadie et al., 2018).

A scientifically dedicated methodical survey of infrastructureassociated marine life can yield quantitative data which is more accurate and useful for informing development proposals, impact assessments and, at end of field life, decommissioning comparative assessments (CAs) or Net Environmental Benefit Analysis assessments (NEBAs) (Nicolette et al., 2013; Sommer et al., 2019). Such programs can be completed with efficiency (e.g., McLean et al., 2019), adding little cost to field campaigns. There are a variety of different ways that dedicated surveys of marine communities associated with infrastructure can occur, with the chosen technique largely dictated by ROV operational logistics. For example, vessel-deployed ROVs may have more maneuverability and therefore capacity to survey a greater proportion of a platform jacket than platform-deployed ROVs. Water currents, structural design/elements and depth of the infrastructure all also influence survey design.

The seafloor and water column surrounding infrastructure can be surveyed using ROVs typically through observation and collection of unknown species (e.g., Pugh et al., 2018), behavioral studies (Haddock et al., 2018), or quantitative evaluation of community structure (Bamstedt et al., 2003). These rely primarily on good quality imaging, precision specimen collection, and video transect surveys (Table 1). These approaches are possible, and many are routine operations for industrial ROVs. In the case of exploration O\&G vessels, the only structure between the rig or ship and the seabed is a small riser. Thus, observations of the water column typically reflect the ambient plankton and nekton with little influence from the riser. Because of the unusual locations of many industry ROV operations, faunal 
observations from industry ROVs have proved valuable in quantifying new distributions (Benfield et al., 2008; Hirai and Jones, 2012; Jones and Pugh, 2018), describing new species (Vecchione et al., 2001), observing new behaviors (Laurenson et al., 2004; Benfield et al., 2013), evidence of reproduction (Todd et al., 2018), and quantifying baseline environmental conditions (Macreadie et al., 2018).

\section{ROV Video Surveys \\ ROV Video Surveys of Infrastructure and the Surrounding Water Column}

Figure 5 illustrates examples of how dedicated ROV visual surveys can be carried out on jackets (Figures 5A-D) and wells (Figures 5E,F) to survey marine growth and fish communities. Surveys of infrastructure communities across depth zones can be obtained by facing the ROV cameras toward the structure during descent and ascent. Offset distances should be carefully chosen for effective survey of the species of interest and this distance maintained (as well as consistent ROV speed). For example, McLean et al. (2019) augmented an industry ROV with stereovideo cameras (Figure 3G) and instructed ROV operators in the collection of imagery from vertical transects of a platform jacket, with surveys conducted independent of scientists at the site of operations. Four surface-to-seabed and return transects took a total of $1.25 \mathrm{~h}$ to complete $(\sim 15$ min per vertical transect) within a scheduled 2 -week ROV field campaign and produced quantitative information on fish diversity, abundance, size structure, and marine growth extent and complexity (McLean et al., 2019).

Further surveys of infrastructure marine communities could be obtained opportunistically by simply facing ROV cameras toward the structure when ROVs are transiting between locations, resting on the seabed, or in the tether management system (TMS) between operations. ROV pilots can be trained to conduct belt transects around the base of infrastructure during ROV down time. Belt transects involve "circling" the structure at a constant speed while maintaining a constant distance and field of view (Love et al., 2000; Figure 5F). Such transects can be quick, taking approximately $90 \mathrm{~s}$ to complete, and can assist the training of less experienced pilots in ROV operations. Resulting opportunistic video has already been used to quantify the abundance and diversity of tropical reef fishes associated with wells and platforms in north-west Australia (Pradella et al., 2014; McLean et al., 2018; Thomson et al., 2018).

HD imagery collected during these surveys provides information on fish diversity, abundance and size (particularly where stereo-cameras are used), of marine growth type, extent and complexity, and of behavioral associations between fauna and structures (McLean et al., 2019). An emerging image processing technique called "Structure from Motion Photogrammetry (SfMP)" can be used to produce spatially referenced 3D models of structures and marine growth using sequences of 2D images (e.g., video frames) acquired from multiple perspectives by a single moving camera (Figure 6). Recurring features within a sequence of overlapping images are used to align images and estimate angle and orientation of the camera for each image. Camera positions are then used to assign $x, y, z$ coordinates to features within images and generate a 3D point cloud (Westoby et al., 2012). A mesh, textured with original source images, can be interpolated between the points to produce the final 3D model (Figueira et al., 2015; Figure 6). If an object(s) with known dimensions and/or location in a real-word coordinate system are included in the images, the $3 \mathrm{D}$ model can be scaled and orientated, and then used to derive the area, volume, and surface roughness of objects or landscapes (Bennecke et al., 2016; Ferrari et al., 2016). For objects (e.g., marine growth species) that have a known density, the volume estimates can be converted into mass (Westoby et al., 2012). $2 \mathrm{D}$ to $3 \mathrm{D}$ reconstruction can be problematic for moving objects (such as fish, or marine mammals, and also moving marine growth), when based on single camera image acquisition, though stereo-camera (Figure 3G) or multi-bank cameras may provide solutions to this problem. In the context of surveys of marine growth on offshore infrastructure, it offers considerable scope for quantification and description of biofouling organisms. An understanding of marine growth type and mass is an urgent priority for research with multisector, multidisciplinary, and global relevance. This is because establishment and colonization of marine growth on subsea infrastructure over time has significant consequences for engineering, both in terms of maintenance and design, while the marine communities themselves deliver ecosystem services including water filtration, carbon sequestration, and fisheries.

\section{ROV Video Surveys of the Seafloor Surrounding Infrastructure}

Seafloor ROV video-transect surveys have proved valuable to quantify benthic disturbance (e.g., Gates and Jones, 2012; Jones et al., 2012). Repeat ROV transect surveys carried out at different phases in drilling operations over time reveal changes to seabed habitats and their potential for recovery. Feasibility of such a time series depends on a plethora of factors such as: cost, project duration, collaboration with industry and wider industry partners (if a consortium of operators). Surveys could occur: (1) before operations (e.g., during baseline surveys before arrival of a drilling rig, or pre-laid pipeline route survey), (2) survey immediately prior to operations ("as found" surveys are often carried from the drilling rig to check the site is safe to drill), (3) at various operational stages throughout drilling (typically 2-3 months), and (4) during subsequent operations at the same site or return visit by ship (Jones et al., 2012).

An ROV launched from stationary oil industry infrastructure such as a production platform (e.g., those in Figure 1), semisubmersible drilling rig, drill ship or jack-up rig will be restricted by tether length to around 100-500 $\mathrm{m}$ of horizontal movement over the seafloor. As a result, the most practical survey strategy is radial transects. Such transects radiate along a disturbance gradient from the well in the center. Video (ideally HD color video) and still images are typically collected continually or at regular intervals along the transect (e.g., as detailed in Jones et al., 2007; Benfield et al., 2019). If not present, augmenting an industry ROV with a high 


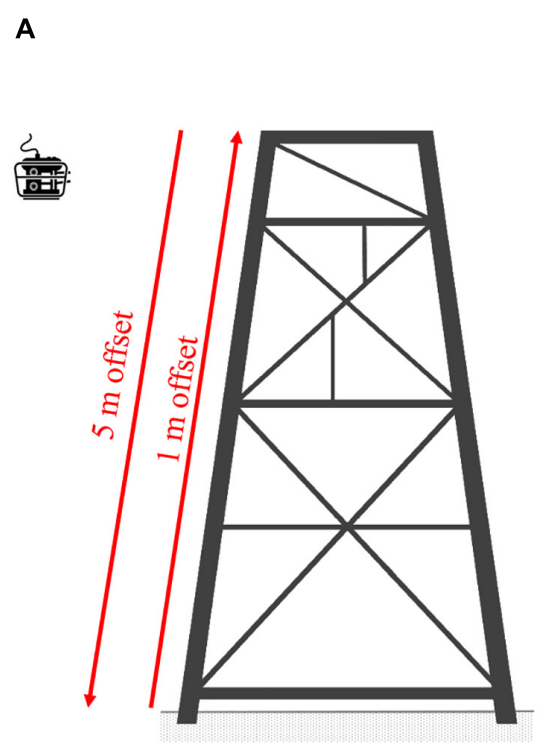

E
B

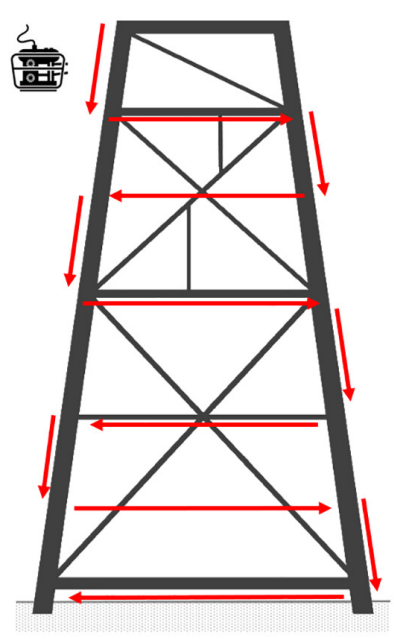

$\mathbf{F}$
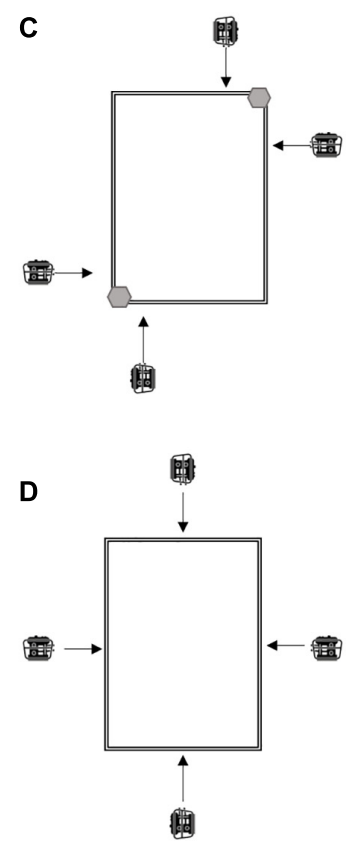
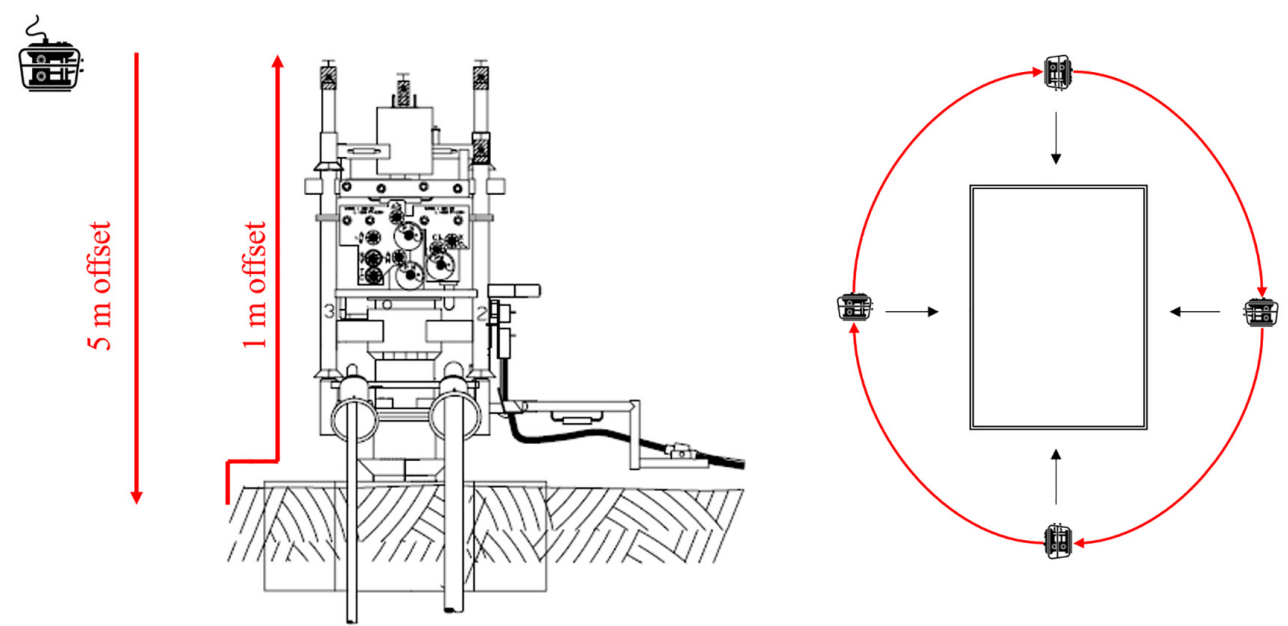

FIGURE 5 | (A) Vertical transects of a platform jacket, (B) horizontal and vertical surveys of a platform jacket, (C) birds eye view of a platform-deployed ROV limited to certain areas of a jacket and (D) birds eye view of vessel-deployed ROV survey of a jacket. (E) Wells are typically $<9 \mathrm{~m}$ in height and surveyed by performing a vertical survey close to and further away and (F) by moving the ROV around the well structure.

resolution photographic camera (and flash/strobe) considerably enhances the quality of observations in these transect surveys. The addition of laser scalers, preferably line projectors, is essential to quantify the field of view. A subsea navigation system (USBL) is desirable to provide precise positioning information. This is particularly important if transects are to be duplicated at a later date. Transects need to be carried out at low altitude, slow speed and with good navigational accuracy to be most useful. With good quality transects, sediment can be classified based on observations of level of coverage of the seafloor by drill cuttings. Quantification of fish and megabenthic invertebrate assemblages (definition $>1 \mathrm{~cm}$, practical definition - visible in photography) is also regularly done (e.g., Jones et al., 2012). Extreme care to avoid use of downward-facing thrusters is essential to prevent disturbance of the sediments which may obscure visibility for an extended period. Consideration of the survey design is required to balance data collection and time constraints. More transects (radial surveys at different headings) enable higher resolution mapping of habitats and disturbance, while replicating headings (with a small offset) enables greater statistical power in assessing impact on fauna. Addition of sediment sampling (Figures 1E, 2B, 3D) can validate visual inspection through measurement of parameters such as hydrocarbon concentration or sediment barium concentration, or by improving taxonomic resolution of faunal identifications. 


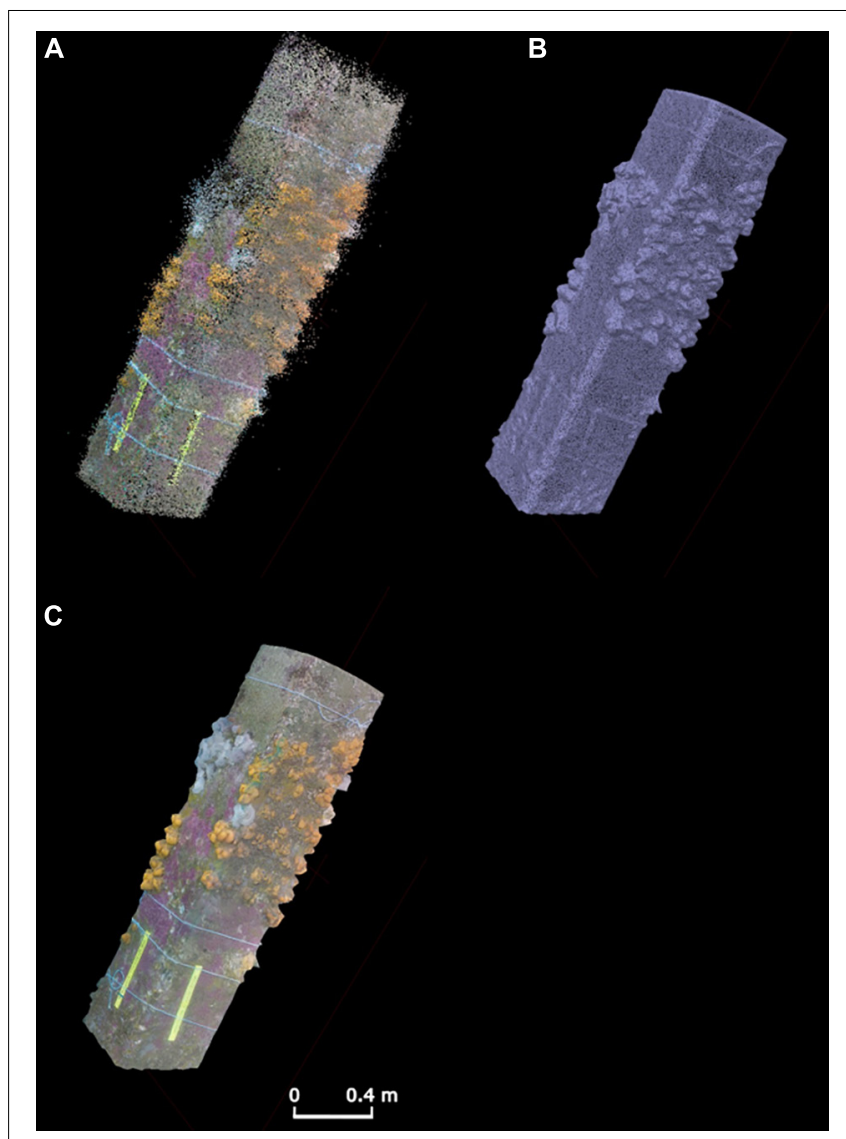

FIGURE 6 | The three stages of 3D model development underpinned by video/photographic imagery including (A) generation of point cloud (B) interpolation into mesh and (C) texturing with source images to produce a final model. Pictured here is a $2-\mathrm{m}$ section of pier (pillar) with soft corals and anemones.

\section{ROV Acoustic Surveys of Infrastructure and Surrounding Environments}

\section{Passive Acoustic Monitoring}

Using ROVs to record sound around infrastructure will help industry understand their impacts in the marine environment. In an often dark, deep or turbid ocean, acoustic cues are vital for many life functions of marine fauna. The importance of sound has been shown in its recognition as an Essential Ocean Variable (EOV) by the Global Ocean Observing System (Goos BioEco, 2018). ROV recordings of sound around O\&G structures provides information on soniferous (sound producing) species present, anthropogenic noise and how the latter impacts the former (Williams et al., 2015; Todd, 2016). Moreover, underwater noise pollution is a serious issue, and the introduction of further anthropogenic noise, such as that generated by O\&G activities (during exploration, construction or operation), often requires permits and use of Marine Mammal Observers (MMOs) and PAM to determine potential effects on marine fauna (Todd et al., 2015, 2016). Such activities add significant cost and operational constraints on offshore projects and are increasingly important components of Environmental Impact Assessments
(EIAs), whether for an individual activity or under shared sector and cross sector "noise budgets." Short-term PAM recordings could be conducted for the duration of an ROV survey, by mounting a recorder on the vehicle, while longer term recordings could be made by using the ROV to deploy a recorder at a designated site.

There is potential for the operational noise of industry ROVs and AUVs to mask signals of interest, particularly where recording systems are mounted on the vehicle. Few reports, however, characterize the noise from ROVs, AUVs or even human-occupied vehicles (HOVs) (Cai et al., 2010; Cai and Bingham, 2011; Stimperta et al., 2019). Communication noise between support crew and the subsea unit may also swamp recordings (Stimperta et al., 2019), while the dominant frequencies of electric vehicles appear to be from the electric motor in the tens to hundreds of $\mathrm{Hz}$, with the only available reported source level (root mean squared) at $146 \mathrm{~dB}$ re $1 \mu \mathrm{Pa}$ (Cai et al., 2010; Cai and Bingham, 2011). Nevertheless, ROVmounted PAM recorders have previously been used to detect various marine fauna (Ura et al., 2006; Mann et al., 2008; Rountree and Juanes, 2010; Rountree et al., 2018). The extent of signal masking by noise from industry ROVs, however, requires investigation. Once an instrument is deployed, a departed ROV would lessen or no longer affect the recording.

Long-term PAM, deployed by an ROV, provides nearcontinuous data on soniferous species around the infrastructure, revealing temporal patterns in their abundance, behavior, migration patterns, and responses to stressors (Figure 4A and Table 1). Taxa that can be investigated using PAM include fish (Erbe et al., 2015; McCauley and Cato, 2016; Parsons et al., 2016), mammals (Todd et al., 2009, 2016), and invertebrates (Radford et al., 2008; McWilliam et al., 2017). Characteristics of the soundscape (the combined natural and anthropogenic sounds in the environment) can help detect changes in ecosystem health and between certain types of habitats (Radford et al., 2010; Kaplan et al., 2015; Gordon et al., 2018).

\section{Acoustic Telemetry}

Tracking the movement and interactions of acoustically tagged marine fauna with subsea infrastructure will help industry understand how their structures may act as artificial reefs (Table 1). Recently, underwater acoustic telemetry tracking of animals has provided scientists with a panoramic view into the marine world and is now an important tool used worldwide in understanding animal movement (Hussey et al., 2015). Transmitters or tags with unique identification codes are either attached or implanted in target species such as fish, turtles and sharks (Figure 4C) and their high-frequency transmissions are detected when within range of acoustic receivers, which can be deployed on infrastructure using ROVs (Figure 4B). Acoustic telemetry can address questions on both fine and large-scale movement of marine fauna and has already shown potential around infrastructure and the surrounding water column (Heupel et al., 2015; Thums et al., 2016; Wilson et al., 2018). Telemetry tracking has been conducted directly from autonomous underwater vehicles (AUVs; White C.F. et al., 2016) and tracking fish and invertebrate movements around artificial 
structures and habitat has provided valuable information on how these habitats are used (Jensen et al., 2000; Abecasis et al., 2013). Gulf red snapper (Lutjanus campechanus), is one of the most economically important reef fish in the Gulf of Mexico (Curtis et al., 2015) and a successful example of how telemetry networks have integrated artificial structures such as $O \& G$ platforms, to better understand species movement, residency, and potentially benefit a major fishery (Topping and Szedlmayer, 2011; Piraino and Szedlmayer, 2014; Froehlich et al., 2019).

Acoustic telemetry currently appears to be the best approach to understanding megafauna interactions with offshore installations (Figure 2E and Table 1). On a broad scale, deploying acoustic receivers (Figure 3B) along continental coastlines will greatly extend telemetry networks around the world (Hussey et al., 2015; Abecasis et al., 2018; Hoenner et al., 2018), which is especially important in remote areas. In these areas, there is substantial potential for numerous $O \& G$ structures, such as platforms, wells and pipelines to become telemetry nodes and fill in the gaps between larger networks. Such an opportunistic grid would not only broaden the coverage of these acoustic telemetry networks, but provide valuable insights into how artificial structures are utilized individually or together, by resident and transient species, respectively.

\section{Active Acoustics}

Single- or split-beam echosounders (Figure 3E and Table 1) can be used to estimate fish biomass around the infrastructure and how distance from the structure influences the assemblage (Stanley and Wilson, 1996, 1998; Wilson et al., 2006). ROVs with mounted echosounders could perform short-term surveys of the water column around infrastructure (Baran et al., 2017; Figure 2F). The detection and quantification of internal waves using upward-looking echosounders ( $\mathrm{Li}$ et al., 2009) provides valuable information for structural design and maintenance (Osborne et al., 1977), but also the transport and vertical distribution and density of plankton (Benoit-Bird et al., 2009), a fundamental food source in the ocean. While internal waves (gravity waves) are best detected by stationary systems, they can also be seen in data captured from mobile platforms (such as ROVs) and can be quantified once the motion of the platform has been accounted for.

Multibeam echosounders are sometimes used aboard ROVs to assist with ROV localization and positioning, mapping seafloor habitat, or checking maintenance issues (Petillot et al., 2002; Biffard et al., 2007; Vralstad et al., 2011). Multibeam can provide detailed 3D information on the seafloor, such as substrate type or sediment deposition and scouring around seafloor structures, and therefore assist in identifying potential fatigue points in structures or quantifying changes in habitat. Textural representations (2D images) of this type of data have been collected aboard ROVs in the past, using sector scanning or sidescan sonar (Orange et al., 2002; Elvander and Hawkes, 2012). Relatively new developments in multibeam echosounders have brought simple-to-use, forward-looking imaging sonars that can provide the same information in front of the ROV and expand that seafloor image as the ROV moves forward (Allotta et al., 2015; Figure 2G). Mapping the changing habitats around new, long-existing or decommissioned (removed) O\&G structures can provide valuable information on how they enhance local habitat (e.g., defining the extent around the platform that is influenced by biota on the structure) and where the substrate changes to an environment more typical of far-field habitat.

Multibeam echosounders (Figure 3F) have also more recently been re-tasked to include water column data (Colbo et al., 2014). Whether positioned on a vessel or on an ROV in the water column, multibeam water column backscatter can be used to provide 3-dimensional maps of subsea structures (Williams et al., 2016), bubble plumes from gas seeps or leaks (Weber et al., 2012), or schools of plankton or individual fish (Parsons et al., 2013; Colbo et al., 2014; Table 1). Structure and marine growth data can be combined with photogrammetry techniques to provide picture quality visualizations and volumetric assessments of structure and marine growth, similar to those of Figure 5. Imaging sonars (Figure 4D) improve the resolution of the acoustic data (at the expense of range), providing near-picture quality images of targets in front of the sonar. Many of these imaging sonars have been simplified for non-technical use and can collect data autonomously. In ecological research, this has provided potential alternative or complementary data to optical techniques (Harvey et al., 2018), whether assessing the abundance, length distribution or behavior of fauna (Becker et al., 2013; Parsons et al., 2014; Lieber et al., 2015). This concept is transferrable to assessments of marine fauna around O\&G infrastructure if mounted on or deployed by ROVs (Rose et al., 2005). ADCPs(Figures 2H, 4G) are commonly used to collect oceanographic water column data and are, on occasion, deployed by ROVs for O\&G purposes (Jones et al., 2006). Such oceanographic data can be of great use for scientific purposes whether providing complementary environmental data for biological studies, or detection of geophysical phenomena, such as internal waves (Scotti and Pineda, 2004), as well as biologically derived backscatter (Bozzano et al., 2014).

\section{ROV Collections of Specimens and Samples}

Industry ROVs with manipulator arms have been used successfully in the field to scrape marine growth, collect water, and sample sediment for eDNA analyses from around offshore installations and pipelines $(\mathrm{MB}, \mathrm{EH}$, unpublished data; Figures 1C, 2C, 3C). The most relevant applications of analyses from these samples to the offshore O\&G sector is: (i) detection of potential alien invasive species (AIS), (ii) baseline monitoring of biota before and after infrastructure is commissioned and (iii) understanding what biota has recruited to infrastructure that is scheduled for decommissioning. Beyond industry applications, these samples also offer valuable ecological data on fishes, coral, sponges, plankton, which provide better scientific understanding of the organisms living in proximity to industry operations.

Sediment sampling push cores (sampling $\sim 0.002 \mathrm{~m}^{2}$ of sediment; Figures 1E, 2B, 3D) and grabs $\left(\sim 0.0625 \mathrm{~m}^{2}\right)$ can be used effectively by industry ROV (Jones, 2009) and such samples used to characterize sediment chemistry, physical properties and biology (quantitative samples of microbes to macrofauna; 
eDNA samples). Samples are important for understanding the characteristics of the range of habitat types created by industry operations (areas impacted by cuttings, potential pollution, scours etc.) as well as natural seafloor conditions. The high temporal-spatial precision in ROV sampling can allow scientific questions (e.g., on the nature of disturbance) to be addressed in a way not possible with other approaches. Typically, replicated sediment samples are taken in each habitat or area of interest, or along a gradient of disturbance. As well as quantitative sediment sampling, it is also possible to obtain good-quality samples of objects of interest, which may be natural (e.g., megafaunal individuals, rocks; Figures 3B,C) or anthropogenic (e.g., garbage, cement, etc.).

\section{ROV Surveys of Areas Undisturbed by O\&G Activity}

Some industry operations take place in areas undisturbed by industrial activity, or at least areas with low levels of disturbance, which could be considered representative of "natural" conditions. These baseline observations may be performed with industry ROVs during surveys of conditions prior to development (exploration drilling, pipelines, etc.), immediately prior to operations (e.g., drilling, platform construction) or during ROV operations distant from more disturbed areas. These surveys are often on the critical path of operations and tend to be focussed on quantitative assessment of seafloor conditions, rather than more time-consuming single point observations. These opportunities can also be used for deployment of equipment for longer term monitoring, such as fixed-point moorings. Results from industry surveys like this have already been important in describing new areas (Jones et al., 2013, 2014) prior to offshore platform placement and subsequent colonization (Todd et al., 2019), and in quantifying natural processes that are poorly known (e.g., carbon fluxes to the seafloor: Lebrato and Jones, 2009; Higgs et al., 2014).

\section{USING HISTORICAL ROV IMAGERY FOR SCIENCE}

The images and video already collected by industry ROVs represent one of the most substantial visual datasets available from our oceans. The global offshore energy industry holds a vast archive comprising millions of hours of underwater video and millions of still images, often collected from locations, habitats and depths rarely encountered by independent researchers (Macreadie et al., 2018). Although not collected for the purposes of scientific research, historical ROV imagery represents a rare and ready-made resource for ocean observation (Macreadie et al., 2018; Levin et al., 2019), with the potential to facilitate investigation of a broad range of ecological, biological, behavioral and oceanographic questions, once adequately screened for quality. Historical ROV imagery has already been used to characterize fauna communities that develop on O\&G infrastructure (Pradella et al., 2014; Rouse et al., 2018; Thomson et al., 2018; McLean et al., 2019) and assess the commercial fishery value of pipelines and wells (McLean et al., 2017, 2018; Bond et al., 2018d). Some archival collections span decades and may even provide insights into the effects of longer-term environmental change on offshore ecosystems.

Despite the potential utility of historical ROV imagery, considerable quality control is required before it can be used reliably for scientific investigation. There are generally a small number of factors that limit the scientific value of ROV imagery; (1) the ROV being too far away (for marine growth) or too close (for fish) to the structure, (2) particles in the water column limiting visibility, (3) inconsistency in speed or position of the ROV that makes imagery jerky/blurry or limits field of view, and (4) poor video resolution. Further, ROVs are often equipped with multiple simultaneously filming cameras with each providing a slightly different view of a structure. In many instances, not all cameras are functional. To assist industry and scientists in the refinement of the amount of ROV imagery that is to be used for assessment of fish and marine growth habitats associated with infrastructure, we provide detail on a simple three-step process that can be used to select appropriate imagery (Supplementary Material). In summary, the steps are:

1. scoring the extent of usable imagery of a structure ( 0 = unusable, 1 = sections usable, $2=$ most usable; with descriptions of the imagery within each category);

2. scoring data resolution that can be obtained from ROV imagery from 0 (unusable) through to 5 (excellent), with descriptions of the imagery within each category and examples of ecological metrics that could be collected for each; and

3. estimating the scientific value of historical ROV imagery. This step combines the scores from Step 1 and 2 into a matrix table that clearly identifies scientific value.

Until recently, most historical ROV imagery has been collected in standard definition. Even if video records are HD resolution, and scenes are well (evenly) lit, with appropriate color balance, images are often inherently low contrast (especially of more distant objects) due to the scattering of light between object and camera, and further degraded by back-scatter and veiling light from suspended particles of diverse sizes. As computing power has increased, however, options are emerging for video image enhancement (e.g., Tang et al., 2019), either processing individual frames, or using information from sequences of frames, to "defog" or otherwise contrast enhance video records. In the future it is likely that such methods will become standard in ROV video analytics.

\section{DATA MANAGEMENT}

Access to and the use of historical ROV imagery and metadata and undertaking new scientific ventures in partnership with the $\mathrm{O} \& \mathrm{G}$ industry inevitably requires strong data management protocols to be implemented and followed. Scientists often encounter a number of hurdles when attempting to access and use data provided by industry. Many companies restrict the use of external portable hard drives for transferring data to scientists external to their organization. Industry often also 
have software programs designed specifically (sometimes inhouse) to view and access ROV metadata with these programs sometimes not available or provided to scientists. Further, industry utilize different ROV contractors, often with these contractors using different data storage and handling platforms. Ease of data management is therefore reliant ultimately on the willingness of industry to share data that are accessible and interpretable by scientists.

Data size can also pose challenges. For example, $1 \mathrm{~h}$ of uncompressed $\mathrm{HD}$ video at $1920 \times 1080$ resolution $(24 \mathrm{~Hz})$ has a file size of approx. $500 \mathrm{~GB}$, compared to approx. $10 \mathrm{~GB}$ when filmed in standard definition $(720 \times 576$ at $24 \mathrm{~Hz})$. A single O\&G operator in north-west Australia can collect up to $5,500 \mathrm{~h}$ of underwater imagery in a year equating to $\sim 2,750$ terabytes of data (uncompressed). For passive acoustic datasets, size is dependent on recording schedule and sampling rate, but processed data from a single logger, recording a 50\% duty cycle can exceed 1 TB within a month. Meanwhile, high-resolution data from multibeam echosounder systems collecting water column data can exceed 1 TB within days, dependent on the "ping rate" employed. Due to the resolution and lower sampling volume of singlebeam echosounders and ADCPs, these datasets can be an order of magnitude lower than those of multibeam systems. Datasets from acoustic telemetry receivers are significantly smaller still, but like those of PAM this is multiplied by the number of sensors deployed in any multi-sensor arrays. Clearly more storage will be needed to facilitate an industry-wide switch to HD and collection of additional scientific data such as that collected using PAM. Improvements and protocols surrounding the exchange of large data from operators to researchers, as well as data manipulation comprising the end-to-end workflow around the analyses of data all require IT systems capable of handling large datasets.

The costs of data management and ownership of the data are also very important considerations. Historically, scientific data were often regarded by scientists as their property. More recently ownership is recognized to lie with an employer. Regardless, strict data ownerships agreements would need to be established and understood at the onset of a project to avoid conflict. Data sharing agreements are also important for scienceindustry partnerships where any restrictions or sensitivities of data use are understood clearly by scientists. Industry must also recognize that scientists require the ability to publish research results in journals and to present them at conferences. In the future it will increasingly be a requirement of funding agencies that scientific data are not only properly managed and stored, but that data are available for others to verify scientific findings or to reuse for other purposes. These activities should be actively encouraged by industry with benefits including an improved understanding of the marine environment that is accessible to all. Superficially, this emerging perspective on data ownership poses a challenge for industry, either because industry has paid for its acquisition, or there is a commercial or intellectual property reason for confidentiality. In practice, however, industry is increasingly realizing the value in data sharing, even with competitors, and the value of sharing data, albeit at an appropriate time, or with caveats, with third parties including scientific researchers. For this sharing to work, industry will find the same data management challenges as academic researchers and will need to collaborate to find effective solutions.

Overall, a grand view of data management would envisage regional and/or international depositories of metadata from science related, industry ROV missions. Such a scheme would make at least metadata freely accessible to enable international, scientific collaborations on broad scale science questions. Data banks already exist for ocean monitoring on both regional and international levels [e.g., Australia’s Integrated Marine Observing System (IMOS) and The Global Ocean Observing System (GOOS)] and their expertise and infrastructure could be easily utilized for this purpose.

\section{FROM ROVS TO MARINE AUTONOMOUS SYSTEMS}

Recent advances in marine autonomous systems (MAS) and sensor technology offer the prospect of substantial improvements in spatial resolution of offshore surveys. There may be efficiency gains over current practice, leading to potentially reduced ship time for equivalent data collection, resulting in potentially significant cost savings, reduced carbon emissions and improved safety (fewer personnel days at sea). Generally, less complex vessels are required for MAS operations, ensuing a larger range of available vessels and cheaper voyages. MAS are therefore used increasingly by industry to support some areas of the offshore O\&G industry, such as geophysical data acquisition (Wynn et al., 2014). Other emerging applications in the oil industry include pipeline inspection (Fernandes et al., 2016), environmental data collection (Pai, 2015), environmental monitoring of decommissioned fields (Jones et al., 2019) and oil spill monitoring (White H. et al., 2016).

Uptake may be increasing, but limitations in key areas of MAS technology - fine scale navigation and battery life - currently prevent MAS completely replacing ROVs. Many of the scientific benefits of ROVs are also applicable to MAS. However, as autonomy is slowly introduced into routine operations, scientists must understand any differences in data collection, and how switching vehicles may impact comparisons to historical datasets using alternative methods. For example, typical ROV visual inspections of pipeline use multiple cameras to obtain a central, port and starboard view of the pipeline while an AUV usually uses a single, central camera. In this instance, the ability to see, identify and count fish that most often reside underneath or in the crevice between the seabed and pipeline (Bond et al., 2018a; McLean et al., 2018) is removed and the value of the survey for documenting fish populations significantly reduced. Potential limitations in data comparison should also be outlined to industry and rigorous method comparisons could be undertaken. Particular attention should be paid to biological data collected from visual observations. Vehicle speed, noise and vibration, and altitude as well as the number of cameras, their positions and quality, and lighting are all likely to change from ROV to MAS; each potentially impacting animal behavior in different, species-specific ways. 


\section{CONCLUSION}

Here we describe a range of sensors, samplers and imaging equipment that can be attached to or used by ROV's during routine inspection, maintenance and control campaigns to collect more robust, quantitative scientific data from the marine environment (Figure 2 and Table 1). The feasibility and importance of augmentation and performing scientific survey work is highlighted in addition to the underutilized yet high valuable historical ROV data held by industry. The enhancements and surveys suggested, while often simple, need industry project managers, engineers and ROV operators to work in partnership with research scientists. Such collaborations improve understanding of needs, priorities and restrictions held by all parties. The projects must also have sufficient science personnel to analyze imagery, specimens and measurements. For video analysis, this can equate to significant hours however, machine learning tools to increase the speed of annotation are advancing. Where possible, industry should look ahead at future ROV schedules to best integrate science, ideally allocating time and budget to promote a successful mission. Pilot studies are particularly beneficial for forging industry-science partnerships, trialing ROV enhancements and determining science value.

For the offshore energy industry, the benefits of enhancing industry ROVs are clear: accurate data to underpin environmental impact/condition assessments and decommissioning comparative assessments, enhanced environmental stewardship and more informed engagement with regulators and the public. The benefits of enhancing ROVs for the scientific community are vast: data can be obtained from the most unexplored regions of our oceans leading to new discoveries, the impacts of infrastructure in our oceans can be assessed and understood, and, importantly, we may better understand how marine life in our oceans is changing. With this knowledge comes improved management and conservation strategies for the sustainability of ocean life.

\section{REFERENCES}

Abdo, D. A., Seager, J. W., Harvey, E. S., McDonald, J. I., Kendrick, G. A., and Shortis, M. R. (2006). Efficiently measuring complex sessile epibenthic organisms using a novel photogrammetric technique. J. Exp. Mar. Bio. Ecol. 339, 120-133. doi: 10.1016/j.jembe.2006.07.015

Abecasis, D., Bentes, L., Lino, P. G., Santos, M. N., and Erzini, K. (2013). Residency, movements and habitat use of adult white seabream (Diplodus sargus) between natural and artificial reefs. Estuar. Coast. Shelf Sci. 118, 80-85. doi: 10.1016/j. ecss.2012.12.014

Abecasis, D., Steckenreuter, A., Reubens, J., Aarestrup, K., Alós, J., Badalamenti, F., et al. (2018). A review of acoustic telemetry in Europe and the need for a regional aquatic telemetry network. Anim. Biotelemetry 6:12. doi: 10.1186/ s40317-018-0156-0

Allotta, B., Costanzi, R., Ridolfi, A., Pascali, M. A., Reggiannini, M., Salvetti, O., et al. (2015). "Acoustic data analysis for underwater archaeological sites detection and mapping by means of autonomous underwater vehicles," in Proceedings of the MTS/IEEE OCEANS 2015 - Genova: Discovering Sustainable Ocean Energy for a New World, (Genova: Institute of Electrical and Electronics Engineers), 1-6. doi: 10.1109/OCEANS-Genova.2015.727 1493

\section{DATA AVAILABILITY STATEMENT}

The datasets generated for this study are available on request to the corresponding author.

\section{AUTHOR CONTRIBUTIONS}

The research presented within the manuscript is original and was contributed to by each of the authors. All authors contributed to the writing and reviewing while DM, MP, AG, CP, DJ, SR, and $\mathrm{EH}$ each additionally contributed to visualization (graphics). All authors agreed with the contents of the manuscript and approved it for publication.

\section{FUNDING}

This research did not receive any specific grant from funding agencies in the public, commercial, or not-for-profit sectors.

\section{ACKNOWLEDGMENTS}

The authors wish to acknowledge the many industry partners that, over the years, have allowed us to utilize industry ROVs and historical imagery. This includes the SERPENT project and industry partners included; Woodside Energy Ltd, Santos, BHP, Chevron, Apache, Inpex, Hurricane Energy Plc, Shell, and BP.

\section{SUPPLEMENTARY MATERIAL}

The Supplementary Material for this article can be found online at: https://www.frontiersin.org/articles/10.3389/fmars. 2020.00220/full\#supplementary-material

Bamstedt, U., Kaartvedt, S., and Youngbluth, M. (2003). An evaluation of acoustic and video methods to estimate the abundance and vertical distribution of jellyfish. J. Plankton Res. 25, 1307-1318. doi: 10.1093/plankt/fbg084

Baran, R., Jùza, T., Tušer, M., Balk, H., Blabolil, P., Ėech, M., et al. (2017). A novel upward-looking hydroacoustic method for improving pelagic fish surveys. Sci. Rep. 7:4823. doi: 10.1038/s41598-017-04953-6

Barker, V. A., and Cowan, J. H. (2018). The effect of artificial light on the community structure of reef-associated fishes at oil and gas platforms in the northern Gulf of Mexico. Environ. Biol. Fishes 101, 153-166. doi: 10.1007/ s10641-017-0688-9

Becker, A., Whitfield, A. K., Cowley, P. D., Järnegren, J., and Næsje, T. F. (2013). Potential effects of artificial light associated with anthropogenic infrastructure on the abundance and foraging behaviour of estuary-associated fishes. J. Appl. Ecol. 50, 43-50. doi: 10.1111/1365-2664.12024

Benfield, M. C., Caruso, J. H., and Sulak, K. J. (2009). In situ observations of two manefishes (Perciformes: Caristiidae) in the mesopelagic zone of the Northern Gulf of Mexico. Copeia 2009, 637-641. doi: 10.1643/CI-08-126

Benfield, M. C., Cook, S., Sharuga, S., and Valentine, M. M. (2013). Five in situ observations of live oarfish Regalecus glesne (Regalecidae) by remotely operated vehicles in the oceanic waters of the northern Gulf of Mexico. J. Fish Biol. 83, 28-38. doi: $10.1111 / \mathrm{jfb} .12144$ 
Benfield, M. C., and Graham, W. M. (2010). In situ observations of Stygiomedusa gigantea in the Gulf of Mexico with a review of its global distribution and habitat. J. Mar. Biol. Assoc. U. K. 90, 1079-1093. doi: 10.1017/ s0025315410000536

Benfield, M. C., Kupchik, M. J., Palandro, D. A., Dupont, J. M., Blake, J. A., and Winchell, P. (2019). Documenting deepwater habitat utilization by fishes and invertebrates associated with Lophelia pertusa on a petroleum platform on the outer continental shelf of the Gulf of Mexico using a remotely operated vehicle. Deep Sea Res. I 149:103045. doi: 10.1016/j.dsr.2019.05.005

Benfield, M. C., Thompson, B. A., and Caruso, J. H. (2008). The second report of a sleeper shark (Somniosus (Somniosus) sp.) from the bathypelagic waters of the Northern Gulf of Mexico. Bull. Mar. Sci. 82, 195-198.

Bennecke, S., Kwasnitschka, T., Metaxas, A., and Dullo, W. C. (2016). In situ growth rates of deep-water octocorals determined from 3D photogrammetric reconstructions. Coral Reefs 35, 1227-1239. doi: 10.1007/s00338-016-1471-7

Benoit-Bird, K. J., Au, W. W. L., and Wisdom, D. W. (2009). Nocturnal light and lunar cycle effects on diel migration of micronekton. Limnol. Oceanogr. 54, 1789-1800. doi: 10.4319/lo.2009.54.5.1789

Biffard, B. R., Preston, J. M., and Ross Chapman, N. (2007). “Acoustic classification with single-beam echosounders: processing methods and theory for isolating effects of the seabed on echoes," in Proceedings of the Oceans Conference Record (IEEE), (Vancouver, BC: Institute of Electrical and Electronics Engineers), 1-8. doi: 10.1109/OCEANS.2007.4449250

Bond, T., Langlois, T. J., Partridge, J. C., Birt, M. J., Malseed, B. E., Smith, L., et al. (2018a). Diel shifts and habitat associations of fish assemblages on a subsea pipeline. Fish. Res. 206, 220-234. doi: 10.1016/j.fishres.2018. 05.011

Bond, T., Partridge, J. C., Taylor, M. D., Cooper, T. F., and McLean, D. L. (2018b). The influence of depth and a subsea pipeline on fish assemblages and commercially fished species. PLoS One 13:e0207703. doi: 10.1371/journal.pone. 0207703

Bond, T., Partridge, J. C., Taylor, M. D., Langlois, T. J., Malseed, B. E., Smith, L. D., et al. (2018c). Fish associated with a subsea pipeline and adjacent seafloor of the North West Shelf of Western Australia. Mar. Environ. Res. 141, 53-65. doi: 10.1016/j.marenvres.2018.08.003

Bond, T., Prince, J., Partridge, J. C., White, D., and McLean, D. L. (2018d). "The value of subsea pipelines to marine biodiversity," in Proceedings of the Offshore Technology Conference Asia, (Kuala Lumpur: Offshore Technology Conference), doi: 10.4043/28240-MS

Bozzano, R., Fanelli, E., Pensieri, S., Picco, P., and Schiano, M. E. (2014). Temporal variations of zooplankton biomass in the Ligurian Sea inferred from long time series of ADCP data. Ocean Sci. 10, 93-105. doi: 10.5194/os-10-93-2014

Brokovich, E., Einbinder, S., Shashar, N., Kiflawi, M., and Kark, S. (2008). Descending to the twilight-zone: changes in coral reef fish assemblages along a depth gradient down to 65 m. Mar. Ecol. Prog. Ser. 371, 253-262. doi: 10.3354/ meps07591

Cai, M., and Bingham, B. (2011). "Passive acoustic detection of a small remotely operated vehicle," in Proceedings of the OCEANS 2011 IEEE - Spain, (Santander: Institute of Electrical and Electronics Engineers), 1-7. doi: 10.1109/OceansSpain.2011.6003555

Cai, M., Sou, I. M., Layman, C., Bingham, B., and Allen, J. (2010). “Characterization of the acoustic signature of a small remotely operated vehicle for detection," in Proceedings of the OCEANS 2010 MTS/IEEE Seattle, (Seattle, WA: Institute of Electrical and Electronics Engineers), 1-7. doi: 10.1109/OCEANS.2010. 5664040

Claisse, J. T., Pondella, D. J., Love, M., Zahn, L. A., Williams, C. M., Williams, J. P., et al. (2014). Oil platforms off California are among the most productive marine fish habitats globally. Proc. Natl. Acad. Sci. U.S.A. 111, 15462-15467. doi: 10.1073/pnas.1411477111

Colbo, K., Ross, T., Brown, C., and Weber, T. (2014). A review of oceanographic applications of water column data from multibeam echosounders. Estuar. Coast. Shelf Sci. 145, 41-56. doi: 10.1016/J.ECSS.2014.04.002

Curtis, J. M., Johnson, M. W., Diamond, S. L., and Stunz, G. W. (2015). Quantifying delayed mortality from barotrauma impairment in discarded red snapper using acoustic telemetry. Mar. Coast. Fish. 7, 434-449. doi: 10.1080/19425120.2015. 1074968

Dziak, R. P., Matsumoto, H., Embley, R. W., Merle, S. G., Lau, T. K., Baumberger, T., et al. (2018). Passive acoustic records of seafloor methane bubble streams on the Oregon continental margin. Deep Res. Part II Top. Stud. Oceanogr. 150, 210-217. doi: 10.1016/j.dsr2.2018.04.001

Elliott, S. A. M., Turrell, W. R., Heath, M. R., and Bailey, D. M. (2017). Juvenile gadoid habitat and ontogenetic shift observations using stereo-video baited cameras. Mar. Ecol. Prog. Ser. 568, 123-135. doi: 10.3354/meps12068

Elvander, J., and Hawkes, G. (2012). "ROVs and AUVs in support of marine renewable technologies," in Proceedings of the OCEANS 2012 MTS/IEEE: Harnessing the Power of the Ocean, (Hampton Roads, VA: Institute of Electrical and Electronics Engineers), 1-6. doi: 10.1109/OCEANS.2012.6405139

Erbe, C., Verma, A., McCauley, R., Gavrilov, A., and Parnum, I. (2015). The marine soundscape of the Perth Canyon. Prog. Oceanogr. 137, 38-51. doi: 10.1016/j. pocean.2015.05.015

Fernandes, V. H., Neto, A. A., and Rodrigues, D. D. (2016). "Pipeline inspection with AUV," in Proceedings of the 2015 IEEE/OES Acoustics in Underwater Geosciences Symposium, RIO Acoustics, (Rio de Janeiro: Institute of Electrical and Electronics Engineers), 1-5. doi: 10.1109/RIOAcoustics.2015.7473607

Ferrari, R., McKinnon, D., He, H., Smith, R., Corke, P., González-Rivero, M., et al. (2016). Quantifying multiscale habitat structural complexity: a cost-effective framework for underwater 3D modelling. Remote Sens. 8:113. doi: 10.3390/ rs8020113

Figueira, W., Ferrari, R., Weatherby, E., Porter, A., Hawes, S., Byrne, M., et al. (2015). Accuracy and precision of habitat structural complexity metrics derived from underwater photogrammetry. Remote Sens. 7, 16883-16900. doi: 10.3390/ rs71215859

Fowler, A. M., Jørgensen, A.-M., Svendsen, J. C., Macreadie, P. I., Jones, D. O., Boon, A. R., et al. (2018). Environmental benefits of leaving offshore infrastructure in the ocean. Front. Ecol. Environ. 16:571-578. doi: 10.1002/fee. 1827

Froehlich, C. Y. M., Garcia, A., and Kline, R. J. (2019). Daily movement patterns of red snapper (Lutjanus campechanus) on a large artificial reef. Fish. Res. 209, 49-57. doi: 10.1016/j.fishres.2018.09.006

Fujii, T., and Jamieson, A. J. (2016). Fine-scale monitoring of fish movements and multiple environmental parameters around a decommissioned offshore oil platform: a pilot study in the North Sea. Ocean Eng. 126, 481-487. doi: 10.1016/j.oceaneng.2016.09.003

Gallager, S. M., Yamazaki, H., and Davis, C. S. (2004). Contribution of fine-scale vertical structure and swimming behavior to formation of plankton layers on Georges Bank. Mar. Ecol. Prog. Ser. 267, 27-43. doi: 10.3354/meps267027

Galloway, K. C., Becker, K. P., Phillips, B., Kirby, J., Licht, S., Tchernov, D., et al. (2016). Soft robotic grippers for biological sampling on deep reefs. Soft Robot. 3, 23-33. doi: 10.1089/soro.2015.0019

Gates, A. R., Benfield, M. C., Booth, D. J., Fowler, A. M., Skropeta, D., and Jones, D. O. B. (2017a). Deep-sea observations at hydrocarbon drilling locations: contributions from the SERPENT project after 120 field visits. Deep Sea Res. Part II Top. Stud. Oceanogr. 137, 463-479. doi: 10.1016/j.dsr2.2016.07.011

Gates, A. R., and Jones, D. O. B. (2012). Recovery of benthic megafauna from anthropogenic disturbance at a hydrocarbon drilling Well (380 $\mathrm{m}$ depth in the Norwegian Sea). PLoS One 7:e44114. doi: 10.1371/journal.pone.0044114

Gates, A. R., Morris, K. J., Jones, D. O. B., and Sulak, K. J. (2017b). An association between a cusk eel (Bassozetus sp.) and a black coral (Schizopathes sp.) in the deep western Indian Ocean. Mar. Biodivers. 47, 971-977. doi: 10.1007/s12526016-0516-Z

Gates, A. R. T., Horton, A., Serpell-Stevens, C., Chandler, L. J., Grange, K., Robert, A., et al. (2019). Ecological role of an offshore industry artificial structure. Front. Mar. Sci. 6:675. doi: 10.3389/fmars.2019.00675

Giacalone, V. M., Anna, G. D., Garofalo, G., Collins, K., and Badalamenti, F. (2005). "Estimation of positioning error from an array of automated omni- directional receivers in an artificial reef area," in Proceedings of the Fifth Conference on Fish Telemetry Held in Europe, Ustica, 245-253.

Goos BioEco (2018). Report of the Third Panel Meeting, 7-9 November 2018. GOOS Biology and Ecosystem Panel, GOOS Report No. \#232 3 Annexes. St. Petersburg, FL: UNESCO, 63.

Gordon, T. A. C., Harding, H. R., Wong, K. E., Merchant, N. D., Meekan, M. G., McCormick, M. I., et al. (2018). Habitat degradation negatively affects auditory settlement behavior of coral reef fishes. Proc. Natl. Acad. Sci. U.S.A. 115, 5193-5198. doi: 10.1073/pnas.1719291115

Guerin, A. J., Jensen, A. C., and Jones, D. (2007). Artificial reef properties of North Sea oil and gas production platforms. Oceans 1-3, 795-800. 
Haddock, S., Christianson, L., Francis, W., Martini, S., Powers, M., Dunn, C., et al. (2018). Insights into the biodiversity, behavior, and bioluminescence of deepsea organisms using molecular and maritime technology. Oceanography 30, 38-47. doi: 10.5670/oceanog.2017.422

Harvey, E., and Shortis, M. (1995). A system for stereo-video measurement of sub-tidal organisms. Mar. Technol. Soc. J. 29, 10-22. doi: 10.1007/s00227-0101404-x

Harvey, E. S., Santana-Garcon, J., Goetze, J. S., Saunders, B. J., and Cappo, M. (2018). "The Use of Stationary Underwater Video for Sampling Sharks," in:Shark Research, eds J. C Carrier, M. R. Heithaus, C. A. Simpfendorfer (Boca Raton, FL: CRC Press). doi: 10.1201/b21842

Heupel, M. R., Simpfendorfer, C. A., Espinoza, M., Smoothey, A. F., Tobin, A., and Peddemors, V. (2015). Conservation challenges of sharks with continental scale migrations. Front. Mar. Sci. 2:12. doi: 10.3389/fmars.2015.00012

Higgs, N. D., Gates, A. R., and Jones, D. O. B. (2014). Fish food in the deep sea: revisiting the role of large food-falls. PLoS One 9:e96016. doi: 10.1371/journal. pone.0096016

Hirai, J., and Jones, D. O. B. (2012). The temporal and spatial distribution of krill (Meganyctiphanes norvegica) at the deep seabed of the Faroe-Shetland Channel, UK: a potential mechanism for rapid carbon flux to deep sea communities. Mar. Biol. Res. 8, 48-60. doi: 10.1080/17451000.2011.594891

Hoeberechts, M., Owens, D., Riddell, D. J., and Robertson, A. D. (2015). “The power of seeing: experiences using video as a deep-sea engagement and education tool," in Proceedings of the OCEANS 2015 - MTS/IEEE Washington, (Washington, DC: Institute of Electrical and Electronics Engineers), 1-9. doi: 10.23919/oceans.2015.7404592

Hoenner, X., Huveneers, C., Steckenreuter, A., Simpfendorfer, C., Tattersall, K., Jaine, F., et al. (2018). Data descriptor: Australia's continental-scale acoustic tracking database and its automated quality control process. Sci. Data 5:170206. doi: $10.1038 /$ sdata.2017.206

Horton, T., and Thurston, M. H. (2015). A revision of the genus Paracallisoma Chevreux, 1903 (Crustacea: Amphipoda: Scopelocheiridae: Paracallisominae) with a redescription of the type species of the genus Paracallisoma and the description of two new genera and two new species from the Atlantic Ocean. Zootaxa 3995, 91-132. doi: 10.11646/zootaxa.3995.1.12

Hoving, H. J. T., Zeidberg, L. D., Benfield, M. C., Bush, S. L., Robison, B. H., and Vecchione, M. (2013). First in situ observations of the deep-sea squid Grimalditeuthis bonplandi reveal unique use of tentacles. Proc. Biol. Sci. 280:20131463. doi: 10.1098/rspb.2013.1463

Hughes, S. J. M., Jones, D. O. B., Hauton, C., Gates, A. R., and Hawkins, L. E. (2010). An assessment of drilling disturbance on Echinus acutus var. norvegicus based on in-situ observations and experiments using a remotely operated vehicle (ROV). J. Exp. Mar. Bio. Ecol. 395, 37-47. doi: 10.1016/J.JEMBE.2010.08.012

Hussey, N. E., Kessel, S. T., Aarestrup, K., Cooke, S. J., Cowley, P. D., Fisk, A. T., et al. (2015). Aquatic animal telemetry: a panoramic window into the underwater world. Science 348:1255642. doi: 10.1126/science.1255642

IMCA (2015). IMCA World-Wide ROV Personnel and Vehicle Statistics for 2014. Richmond, VA: International Marine Contractors Association.

Jarman, S. N., Berry, O., and Bunce, M. (2018). The value of environmental DNA biobanking for long-term biomonitoring. Nat. Ecol. Evol. 2, 1192-1193. doi: 10.1038/s41559-018-0614-3

Jensen, A., Collins, K., and Smith, P. (2000). "The poole bay artificial reef project," in Artificial Reefs in European Seas, eds A. C. Jensen, K. J. Collins, and A. P. M. Lockwood (Dordrecht: Springer), 263-287. doi: 10.1007/978-94-011-42 15-1_16

Jones, D. O. B. (2009). Using existing industrial remotely operated vehicles for deep-sea science. Zool. Scripta 38, 41-47. doi: 10.1111/j.1463-6409.2007.00 315. $\mathrm{x}$

Jones, D. O. B., and Brewer, M. E. (2012). Response of megabenthic assemblages to different scales of habitat heterogeneity on the Mauritanian slope. Deep Res. Part I Oceanogr. Res. Pap. 67, 98-110. doi: 10.1016/j.dsr.2012.05.006

Jones, D. O. B., Gates, A. R., Huvenne, V. A. I., Phillips, A. B., and Bett, B. J. (2019). Autonomous marine environmental monitoring: application in decommissioned oil fields. Sci. Total Environ. 668, 835-853. doi: 10.1016/J. SCITOTENV.2019.02.310

Jones, D. O. B., Gates, A. R., and Lausen, B. (2012). Recovery of deep-water megafaunal assemblages from hydrocarbon drilling disturbance in the FaroeShetland Channel. Mar. Ecol. Prog. Ser. 461, 71-82. doi: 10.3354/meps09827
Jones, D. O. B., Hudson, I. R., and Bett, B. J. (2006). Effects of physical disturbance on the cold-water megafaunal communities of the Faroe-Shetland Channel. Mar. Ecol. Prog. Ser. 319, 43-54. doi: 10.3354/meps319043

Jones, D. O. B., Mrabure, C. O., and Gates, A. R. (2013). Changes in deep-water epibenthic megafaunal assemblages in relation to seabed slope on the Nigerian margin. Deep Sea Res. Part I Oceanogr. Res. Pap. 78, 49-57. doi: 10.1016/J.DSR. 2013.04.005

Jones, D. O. B., and Pugh, P. R. (2018). First sighting of a siphonophore of the genus Bathyphysa from the South Atlantic. Mar. Biodivers. 48, 1279-1280. doi: 10.1007/s12526-016-0611-1

Jones, D. O. B., Walls, A., Clare, M., Fiske, M. S., Weiland, R. J., O’Brien, R., et al. (2014). Asphalt mounds and associated biota on the Angolan margin. Deep Sea Res. Part I Oceanogr. Res. Pap. 94, 124-136. doi: 10.1016/J.DSR.2014.08.010

Jones, D. O. B., Wigham, B. D., Hudson, I. R., and Bett, B. J. (2007). Anthropogenic disturbance of deep-sea megabenthic assemblages: a study with remotely operated vehicles in the Faroe-Shetland Channel. NE Atlantic Mar. Biol. 151, 1731-1741. doi: 10.1007/s00227-007-0606-3

Kaplan, M. B., Mooney, T. A., Partan, J., and Solow, A. R. (2015). Coral reef species assemblages are associated with ambient soundscapes. Mar. Ecol. Prog. Ser. 533, 93-107. doi: 10.3354/meps11382

Katija, K., Sherlock, R. E., Sherman, A. D., and Robison, B. H. (2017). New technology reveals the role of giant larvaceans in oceanic carbon cycling. Sci. Adv. 3:e1602374. doi: 10.1126/sciadv.1602374

Koslow, J. A. (2009). The role of acoustics in ecosystem-based fishery management. ICES J. Mar. Sci. 66, 966-973. doi: 10.1093/icesjms/fsp082

Kupchik, M. J., Benfield, M. C., and Sutton, T. T. (2018). The first in situ encounter of Gigantura chuni (Giganturidae: Giganturoidei: Aulopiformes: Cyclosquamata: Teleostei), with a preliminary investigation of pair-bonding. Copeia 106, 641-645. doi: 10.1643/ce-18-034

Laurenson, C. H., Hudson, I. R., Jones, D. O. B., and Priede, I. G. (2004). Deep water observations of Lophius piscatorius in the north-eastern Atlantic Ocean by means of a remotely operated vehicle. J. Fish Biol. 65, 947-960. doi: 10.1111/ j.0022-1112.2004.00496.x

Lebrato, M., and Jones, D. O. B. (2009). Mass deposition event of Pyrosoma atlanticum carcasses off Ivory Coast (West Africa). Limnol. Oceanogr. 54, 1197-1209. doi: 10.4319/lo.2009.54.4.1197

Levin, L. A., Bett, B. J., Gates, A. R., Heimbach, P., Howe, B. M., Janssen, F., et al. (2019). Global observing needs in the deep ocean. Front. Mar. Sci. 6:241. doi: $10.3389 /$ fmars.2019.00241

Li, Q., Farmer, D. M., Duda, T. F., and Ramp, S. (2009). Acoustical measurement of nonlinear internal waves using the inverted echo sounder. J. Atmos. Ocean. Technol. 26, 2228-2242. doi: 10.1175/2009JTECHO652.1

Lieber, L., Williamson, B., and Kuus, P. (2015). Tracking UK basking sharks with a teledyne RESON SeaBat 7128: basking in the dark. Hydro Int. 19, 18-21.

Love, M. S., Caselle, J. E., and Snook, L. (2000). Fish assemblages around seven oil platforms in the Santa Barbara Channel area. Fish. Bull. 98, 96-117.

Love, M. S., Schroeder, D. M., Lenarz, W., MacCall, A., Bull, A. S., and Thorsteinson, L. (2006). Potential use of offshore marine structures in rebuilding an overfished rockfish species, bocaccio (Sebastes paucispinis). Fish. Bull. 104, 383-390.

Macreadie, P. I., Fowler, A. M., and Booth, D. J. (2011). Rigs-to-reefs: will the deep sea benefit from artificial habitat? Front. Ecol. Environ. 9:455-461. doi: 10.1890/100112

Macreadie, P. I., McLean, D. L., Thomson, P. G., Partridge, J. C., Jones, D. O. B., Gates, A., et al. (2018). Eyes in the sea: unlocking the mysteries of the ocean using industrial, remotely operated vehicles (ROVs). Sci. Total Environ. 634, 1077-1091. doi: 10.1016/J.SCITOTENV.2018.04.049

Mann, D., Locascio, J., Schärer, M., Koenig, C., Nemeth, M., Nelson, M., et al. (2008). Passive acoustic detection of grouper sound production. J. Acoust. Soc. Am. 123, 3098-3098. doi: 10.1121/1.2932954

Marsh, L., Copley, J. T., Huvenne, V. A. I., Tyler, P. A., and the Isis Rov Facility (2013). Getting the bigger picture: using precision remotely operated vehicle (ROV) videography to acquire high-definition mosaic images of newly discovered hydrothermal vents in the Southern Ocean. Deep Sea Res. Part II Top. Stud. Oceanogr. 92, 124-135. doi: 10.1016/J.DSR2.2013.02.007

McCauley, R. D., and Cato, D. H. (2016). Evening choruses in the Perth Canyon and their potential link with Myctophidae fishes. J. Acoust. Soc. Am. 140, 2384-2398. doi: 10.1121/1.4964108 
McLean, D. L., Macreadie, P., White, D. J., Thomson, P. G., Fowler, A., Gates, A. R., et al. (2018). "Understanding the global scientific value of industry ROV data, to quantify marine ecology and guide offshore decommissioning strategies," in Proceedings of the Offshore Technology Conference Asia, Kuala Lumpur, Malaysia, 20-23 March, (Houston, TX: Offshore Technology Conference), doi: 10.4043/28312-MS

McLean, D. L., Partridge, J. C., Bond, T., Birt, M. J., Bornt, K. R., and Langlois, T. J. (2017). Using industry ROV videos to assess fish associations with subsea pipelines. Cont. Shelf Res. 141, 76-97. doi: 10.1016/j.csr.2017.05.006

McLean, D. L., Taylor, M. D., Giraldo Ospina, A., and Partridge, J. C. (2019). An assessment of fish and marine growth associated with an oil and gas platform jacket using an augmented remotely operated vehicle. Cont. Shelf Res. 179, 66-84. doi: 10.1016/j.csr.2019.04.006

McWilliam, J. N., McCauley, R. D., Erbe, C., and Parsons, M. J. G. (2017). Patterns of biophonic periodicity on coral reefs in the Great Barrier Reef. Sci. Rep. 7:17459. doi: 10.1038/s41598-017-15838-z

Nguyen, T. T., Cochrane, S. K. J., and Landfald, B. (2018). Perturbation of seafloor bacterial community structure by drilling waste discharge. Mar. Poll. Bull. 129, 615-622. doi: 10.1016/j.marpolbul.2017.10.039

Nicolette, J., Burr, S., and Rockel, M. (2013). A practical approach for demonstrating environmental sustainability and stewardship through a net ecosystem service analysis. Sustain. 5, 2152-2177. doi: 10.3390/su5052152

Orange, D. L., Yun, J., Maher, N., Barry, J., and Greene, G. (2002). Tracking California seafloor seeps with bathymetry, backscatter and ROVs. Cont. Shelf Res. 22, 2273-2290. doi: 10.1016/S0278-4343(02)00054-7

Osborne, A. R., Brown, J. R., Burch, T. L., and Scarlet, R. I. (1977). “The influence of internal waves on deepwater drilling operations," in Proceedings of the Offshore Technology Conference, May 2-5, 1977, Houston, TX, doi: 10.4043/2797-MS

Pai, S. (2015). "Autonomous marine vehicle: a cost effective technology to manage risk in exploration and production," in Proceedings of the SPE Annual Technical Conference and Exhibition. Society of Petroleum Engineers, Houston, TX, doi: 10.2118/174924-ms

Parsons, M. J. G., Parnum, I. M., Allen, K., McCauley, R. D., and Erbe, C. (2014). Detection of sharks with the Gemini imaging sonar. Acoust. Aust. 42, 185-190.

Parsons, M. J. G., Parnum, I. M., and McCauley, R. D. (2013). Visualizing Samsonfish (Seriola hippos) with a Reson 7125 Seabat multibeam sonar. ICES J. Mar. Sci. 70, 665-674. doi: 10.1093/icesjms/fst009

Parsons, M. J. G., Salgado-Kent, C. P., Marley, S. A., Gavrilov, A. N., and McCauley, R. D. (2016). Characterizing diversity and variation in fish choruses in Darwin Harbour. ICES J. Mar. Sci. 73, 2058-2074. doi: 10.1093/icesjms/fsw037

Petillot, Y. R., Reed, S. R., and Bell, J. M. (2002). "Real time AUV pipeline detection and tracking using side scan sonar and multi-beam echo-sounder," in Proceedings of the Oceans '02 MTS/IEEE, (Biloxi, MI), 217-222. doi: 10.1109/ oceans.2002.1193275

Phillips, N. D., Harrod, C., Gates, A. R., Thys, T. M., and Houghton, J. D. R. (2015). Seeking the sun in deep, dark places: mesopelagic sightings of ocean sunfishes (Molidae). J. Fish. Biol. 87, 1118-1126. doi: 10.1111/jfb.12769

Piraino, M. N., and Szedlmayer, S. T. (2014). Fine-scale movements and home ranges of red snapper around artificial reefs in the northern Gulf of Mexico. Trans. Am. Fish. Soc. 143, 988-998. doi: 10.1080/00028487.2014.901249

Pradella, N., Fowler, A. M., Booth, D. J., and Macreadie, P. I. (2014). Fish assemblages associated with oil industry structures on the continental shelf of north-western Australia. J. Fish Biol. 84, 247-255. doi: 10.1111/jfb.12274

Pugh, P. R., Dunn, C. W., and Haddock, S. H. D. (2018). Description of Tottonophyes enigmatica gen. nov., sp. nov. (Hydrozoa, Siphonophora, Calycophorae), with a reappraisal of the function and homology of nectophoral canals. Zootaxa 4415, 452-472. doi: 10.11646/zootaxa.4415.3.3

Radford, C., Jeffs, A., Tindle, C., and Montgomery, J. C. (2008). Resonating sea urchin skeletons create coastal choruses. Mar. Ecol. Prog. Ser. 362, 37-43. doi: 10.3354/meps07444

Radford, C. A., Stanley, J. A., Tindle, C. T., Montgomery, J. C., and Jeffs, A. G. (2010). Localised coastal habitats have distinct underwater sound signatures. Mar. Ecol. Prog. Ser. 401, 21-29. doi: 10.3354/meps08451

Richardson, W. J., Greene, C. R., Malme, C. I., Thomson, D. H., Moore, S. E., and Wiirsig, B. (2013). Marine Mammals and Noise. Amsterdam: Elsevier, doi: 10.1016/C2009-0-02253-3
Robert, K., Huvenne, V. A. I., Georgiopoulou, A., Jones, D. O. B., Marsh, L., Carter, D. O. G., et al. (2017). New approaches to high-resolution mapping of marine vertical structures. Sci. Rep. 7:9005. doi: 10.1038/s41598-017-09382-z

Roberts, J. M., Wheeler, A. J., and Freiwald, A. (2006). Reefs of the deep: the biology and geology of cold-water coral ecosystems. Science 312, 543-547. doi: 10.1126/science.1119861

Rose, C. S., Stoner, A. W., and Matteson, K. (2005). Use of high-frequency imaging sonar to observe fish behaviour near baited fishing gears. Fish. Res. 76, 291-304. doi: 10.1016/j.fishres.2005.07.015

Rountree, R. A., Goudey, C. A., Hawkins, A. D., Luczkovich, J. J., and Mann, D. A. (2003). Listening to Fish: Passive Acoustic Applications in Marine Fisheries. Cambridge, MA: Sea Grant Digital Oceans.

Rountree, R. A., and Juanes, F. (2010). First attempt to use a remotely operated vehicle to observe soniferous fish behavior in the Gulf of Maine, Western Atlantic Ocean. Curr. Zool. 56, 90-99. doi: 10.1093/czoolo/56.1.90

Rountree, R. A., Juanes, F., and Blue, J. E. (2002). "Potential for the use of remotely operated vehicles (ROVs) as a platform for passive acoustics," in Proceedings of the An International Workshop on the Applications of Passive Acoustics in Fisheries, Dedham, MA.

Rouse, S., Kafas, A., Catarino, R., and Peter, H. (2018). Commercial fisheries interactions with oil and gas pipelines in the North Sea: considerations for decommissioning. ICES J. Mar. Sci. 75, 279-286. doi: 10.1093/icesjms/fsx121

Salim, S., Pattiaratchi, C. B., Tinoco, R. O., and Jayaratne, R. (2018). Sediment resuspension due to near-bed turbulent effects: a deep sea case study on the northwest continental slope of Western Australia. J. Geophys. Res Oceans 23, 7102-7119. doi: 10.1029/2018jc013819

Schroeder, D. M., and Love, M. S. (2004). Ecological and political issues surrounding decommissioning of offshore oil facilities in the Southern California Bight. Ocean Coast. Manag. 47, 21-48. doi: 10.1016/j.ocecoaman. 2004.03.002

Scotti, A., and Pineda, J. (2004). Observation of very large and steep internal waves of elevation near the Massachusetts coast. Geophys. Res. Lett. 31, 1-5. doi: 10.1029/2004GL021052

Shortis, M. R., and Harvey, E. S. (1998). Design and calibration of an underwater stereo-video system for the monitoring of marine fauna populations. Int. Arch. Photogramm. Remote Sens. 32, 792-799. doi: 10.1017/CBO9781107415324.004

Sommer, B., Fowler, A. M., Macreadie, P. I., Palandro, D. A., Aziz, A. C., and Booth, D. J. (2019). Decommissioning of offshore oil and gas structures-environmental opportunities and challenges. Sci. Total Environ. 658, 973-981. doi: 10.1016/j. scitotenv.2018.12.193

Spanier, E., Cobb, J. S., and Clancy, M. (1994). Impacts of remotely operated vehicles (ROVs) on the behavior of marine animals: an example using American lobsters. Mar. Ecol. Prog. Ser 104, 257-266. doi: 10.3354/meps104257

Stanley, D. R., and Wilson, C. A. (1996). Abundance of fishes associated with a petroleum platform as measured with dual-beam hydroacoustics. ICES J. Mar. Sci. 53, 473-475. doi: 10.1006/jmsc.1996.0067

Stanley, D. R., and Wilson, C. A. (1998). Spatial variation in fish density at three petroleum platforms as measured with dual-beam hydroacoustics. Gulf Mex. Sci. 16, 73-82. doi: 10.18785/goms.1601.11

Stanley, D. R., and Wilson, C. A. (2000). Variation in the density and species composition of fishes associated with three petroleum platforms using dual beam hydroacoustics. Fish. Res. 47, 161-172. doi: 10.1016/s0165-7836(00) 00167-3

Stimperta, A. K., Madrigal, B. C., Wakefield, W. W., and Yoklavich, M. M. (2019). Acoustic influence of underwater mobile survey vehicles on the soundscape of Pacific rockfish habitat. J. Acoust. Soc. Am. 146, EL45-EL51. doi: 10.1121/ 1.5109914

Taberlet, P., Bonin, A., Zinger, L., and Coissac, E. (2018). Environmental DNA. Oxford: Oxford University Press, doi: 10.1093/oso/9780198767220.001.0001

Tang, C., von Lukas, U. F., Vahl, M., Wang, S., Wang, Y., and Tan, M. (2019). Efficient underwater image and video enhancement based on Retinex. Signal Image Video P. 13, 1011-1018. doi: 10.1007/s11760-019-01439-y

Thomson, P. G., Fowler, A. M., Davis, A. R., Pattiaratchi, C. B., and Booth, D. J. (2018). Some Old movies become classics - a case study determining the scientific value of ROV inspection footage on a platform on Australia's North West Shelf. Front. Mar. Sci. 5:471. doi: 10.3389/fmars.2018.00471 
Thums, M., Whiting, S. D., Reisser, J., Pendoley, K. L., Pattiaratchi, C. B., Proietti, M., et al. (2016). Artificial light on water attracts turtle hatchlings during their near shore transit. R. Soc. Open Sci. 3:160142. doi: 10.1098/rsos.160142

Todd, V. L. G. (2016). Mitigation of underwater anthropogenic noise and marine mammals: the 'death of a thousand' cuts and/or mundane adjustment? Mar. Pollut. Bull. 102, 1-3. doi: 10.1016/j.marpolbul.2015.11.059

Todd, V. L. G., Lavallin, E. W., and Macreadie, P. I. (2018). Quantitative analysis of fish and invertebrate assemblage dynamics in association with a North Sea oil and gas installation complex. Mar. Environ. Res. 142, 69-79. doi: 10.1016/j. marenvres.2018.09.018

Todd, V. L. G., Pearse, W. D., Tregenza, N. C., Lepper, P. A., and Todd, I. B. (2009). Diel echolocation activity of harbour porpoises (Phocoena phocoena) around North Sea offshore gas installations. ICES J. Mar. Sci. 66, 734-745. doi: 10.1093/icesjms/fsp035

Todd, V. L. G., Todd, I. B., Gardiner, J. C., and Morrin, E. C. N. (2015). Marine Mammal Observer and Passive Acoustic Monitoring Handbook. Exeter: Pelagic Publishing Ltd.

Todd, V. L. G., Warley, J. C., and Todd, I. B. (2016). Meals on wheels? A decade of megafaunal visual and acoustic observations from offshore Oil \& Gas rigs and platforms in the North and Irish Seas. PLoS One 11:e0153320. doi: 10.1371/ journal.pone.0153320

Todd, V. L. G., Williamson, L. D., Cox, S. E., Todd, I. B., and Macreadie, P. I. (2019). Characterizing the first wave of fish and invertebrate colonization on a new offshore petroleum platform. ICES J. Mar. Sci. doi: 10.1093/icesjms/fs z077

Topping, D. T., and Szedlmayer, S. T. (2011). Home range and movement patterns of red snapper (Lutjanus campechanus) on artificial reefs. Fish. Res. 112, 77-84. doi: 10.1016/j.fishres.2011.08.013

Ura, T., Kojima, J., Nakano, T., Sugimatus, H., Mori, K., Hirotsu, R., et al. (2006). "Experimental result of AUV-based acoustic tracking system of sperm whales," in Proceedings of the OCEANS 2006 - Asia Pacific, (Singapore: Institute of Electrical and Electronics Engineers), 1-5. doi: 10.1109/OCEANSAP.2006. 4393909

Vecchione, M., Young, R. E., Guerra, A., Lindsay, D. J., Clague, D. A., Bernhard, J. M., et al. (2001). Worldwide observations of remarkable deep-sea squids. Science 294, 2505-2506. doi: 10.1126/science.294.5551.2505

Visbeck, M. (2018). Ocean science research is key for a sustainable future. Nat. Commun. 9:690. doi: 10.1038/s41467-018-03158-3

Vralstad, T., Melbye, A. G., Carlsen, I. M., and Llewelyn, D. (2011). Comparison of leak-detection technologies for continuous monitoring of subseaproduction templates. SPE Proj. Facil. Constr. 6, 96-103. doi: 10.2118/1365 90-pa

Weber, T. C., Mayer, L., Beaudoin, J., Jerram, K., Malik, M., Shedd, B., et al. (2012). Mapping gas seeps with the deepwater multibeam echosounder on okeanos explorer. Oceanography 25, 54-55.

Westoby, M. J., Brasington, J., Glasser, N. F., Hambrey, M. J., and Reynolds, J. M. (2012). "Structure-from-Motion" photogrammetry: a low-cost, effective tool for geoscience applications. Geomorphology 179, 300-314. doi: 10.1016/j. geomorph.2012.08.021

White, C. F., Lin, Y., Clark, C. M., and Lowe, C. G. (2016). Human vs robot: comparing the viability and utility of autonomous underwater vehicles for the acoustic telemetry tracking of marine organisms. J. Exp. Mar. Bio. Ecol. 485, 112-118. doi: 10.1016/j.jembe.2016.08.010

White, H., Commy, R., MacDonald, I., and Reddy, C. (2016). Methods of oil detection in response to the deepwater horizon oil spill. Oceanography 29, 76-87. doi: 10.5670/oceanog.2016.72

Widder, E. A., Robison, B. H., Reisenbichler, K. R., and Haddock, S. H. D. (2005). Using red light for in situ observations of deep-sea fishes. Deep Sea Res. Part 1. Oceanogr. Res. Pap. 52, 2077-2085. doi: 10.1016/j.dsr.2005.06.007

Williams, R., Wright, A. J., Ashe, E., Blight, L. K., Bruintjes, R., Canessa, R., et al. (2015). Impacts of anthropogenic noise on marine life: publication patterns, new discoveries, and future directions in research and management. Ocean Coast. Manag. 115, 17-24. doi: 10.1016/j.ocecoaman.2015.05.021

Williams, S. B., Pizarro, O., and Foley, B. (2016). "Return to Antikythera: MultiSession SLAM Based AUV Mapping of a First Century B.C. Wreck Site,"in Springer Tracts in Advanced Robotics, eds D. Wettergreen, and T. Barfoot (Cham: Springer), 45-59. doi: 10.1007/978-3-319-27702-8_4

Wilson, C. A., Miller, M. W., Allen, Y. C., Boswell, K. M., and Neiland, D. L. (2006). Effects of Depth, Location, and Habitat Type on Relative Abundance and Species Composition of Fishes Associated with Petroleum Platforms and Sonnier Bank in the Northern Gulf of Mexico. New Orleans OCS Study MMS 2006-2037. Washington, DC: Minerals Management Service.

Wilson, P., Thums, M., Pattiaratchi, C., Meekan, M., Pendoley, K., Fisher, R., et al. (2018). Artificial light disrupts the nearshore dispersal of neonate flatback turtles Natator depressus. Mar. Ecol. Prog. Ser. 600, 179-192. doi: 10.3354/ meps 12649

Wynn, R. B., Huvenne, V. A. I., Le Bas, T. P., Murton, B. J., Connelly, D. P., Bett, B. J., et al. (2014). Autonomous underwater vehicles (AUVs): their past, present and future contributions to the advancement of marine geoscience. Mar. Geol. 352, 451-468. doi: 10.1016/j.margeo.2014.03.012 doi: 10.1016/j.margeo.2014. 03.012

Conflict of Interest: The authors declare that the research was conducted in the absence of any commercial or financial relationships that could be construed as a potential conflict of interest.

Copyright (C) 2020 McLean, Parsons, Gates, Benfield, Bond, Booth, Bunce, Fowler, Harvey, Macreadie, Pattiaratchi, Rouse, Partridge, Thomson, Todd and Jones. This is an open-access article distributed under the terms of the Creative Commons Attribution License (CC BY). The use, distribution or reproduction in other forums is permitted, provided the original author(s) and the copyright owner(s) are credited and that the original publication in this journal is cited, in accordance with accepted academic practice. No use, distribution or reproduction is permitted which does not comply with these terms. 